\title{
Interval MULTIMOORA method with target values of attributes based on interval distance and preference degree: biomaterials selection
}

\author{
Arian Hafezalkotob $^{1} \cdot$ Ashkan Hafezalkotob $^{2}$
}

Received: 16 March 2016/Accepted: 7 November 2016/Published online: 21 December 2016

(c) The Author(s) 2016. This article is published with open access at Springerlink.com

\begin{abstract}
A target-based MADM method covers beneficial and non-beneficial attributes besides target values for some attributes. Such techniques are considered as the comprehensive forms of MADM approaches. Target-based MADM methods can also be used in traditional decisionmaking problems in which beneficial and non-beneficial attributes only exist. In many practical selection problems, some attributes have given target values. The values of decision matrix and target-based attributes can be provided as intervals in some of such problems. Some target-based decision-making methods have recently been developed; however, a research gap exists in the area of MADM techniques with target-based attributes under uncertainty of information. We extend the MULTIMOORA method for solving practical material selection problems in which material properties and their target values are given as interval numbers. We employ various concepts of interval computations to reduce degeneration of uncertain data. In this regard, we use interval arithmetic and introduce innovative formula for interval distance of interval numbers to create interval target-based normalization technique. Furthermore, we use a pairwise preference matrix based on the concept of degree of preference of interval numbers to calculate the maximum, minimum, and ranking of these numbers. Two decision-making problems
\end{abstract}

Ashkan Hafezalkotob

a_hafez@azad.ac.ir; hafezalkotob@alumni.iust.ac.ir

1 Department of Mechanical Engineering, Islamic Azad University, South Tehran Branch, Ahang Ave, Mahalati Blv, Tehran, Iran

2 Department of Industrial Engineering, Islamic Azad University, South Tehran Branch, Entezari Aly, Oskoui St, Choobi Brg, 1151863411 Tehran, Iran regarding biomaterials selection of hip and knee prostheses are discussed. Preference degree-based ranking lists for subordinate parts of the extended MULTIMOORA method are generated by calculating the relative degrees of preference for the arranged assessment values of the biomaterials. The resultant rankings for the problem are compared with the outcomes of other target-based models in the literature.

Keywords MULTIMOORA - Multiple attribute decisionmaking · Target-based attributes - Interval distance . Preference degree $\cdot$ Biomaterials selection

\section{Introduction}

Engineers often deal with the problem of selecting materials for the design projects. Because of advances in materials science and the related manufacturing technologies, a huge number of materials are now available from which engineers must make a selection for a specific design (Murray 1997). New materials are being produced at a rapid pace. New materials like composites and shapememory alloys usually display superior properties comparing the traditional materials. However, they may have some defects in special applications. Therefore, the selection of materials can be a complex task that requires great academic knowledge and practical experience. Multiple attribute decision-making (MADM) approach can establish a mathematical structure for the process of materials selection.

Target-based MADM techniques can be key tools for decision-making in many real-world applications in which target or goal values are desired for some attributes besides beneficial and non-beneficial attributes. Given that all kinds 
of attributes are considered in target-based MADM, it can be the comprehensive form of traditional decision-making with multiple attributes. In a number of material selection problems, the chosen materials for a product should be compatible with other materials available in the system. Therefore, given target values are considered for materials properties to ensure compatibility between materials (Farag 2013). For example, a target value for the thermal expansion coefficient is important in the selection process of electrical insulating materials (Jahan and Edwards 2015). Hardness of material is another target-based attribute that its value should be controlled (Cavallini et al. 2013; Liu et al. 2014). Density and elastic modulus can also be considered as target-based attributes to have a compatible design. These two material properties are especially important to select suitable biomaterials for implants and prostheses (Bahraminasab et al. 2014; Hafezalkotob and Hafezalkotob 2015; Jahan and Edwards 2013b). The materials selected for prostheses are required to have similar properties to human body tissues (Jahan and Edwards 2013b). The application of target-based MADM techniques is not only limited to selection of materials. For instance, Zeng et al. (2013) developed a normalization technique based on distance to goal values to formulate an extension of the VIKOR approach (from visekriterijumska optimizacija i kompromisno resenje in Serbian that means multi-criteria optimization and compromise solution) for a practical case regarding healthcare management. Aghajani Mir et al. (2016) utilized the target-based models of the technique for order of preference by similarity to ideal solution (TOPSIS) and VIKOR method to rank municipal solid waste management methods. In many real-world selection problems, ratings of alternatives on attributes are presented as ranges of information. The uncertain data may be degenerated and utilized in crisp MADM models. However, degeneration of intervals leads to loss of information. Interval MADM methods help in reduction of data degeneration and produce more robust results.

The multi-objective optimization by ratio analysis (MOORA) technique was introduced by Brauers and Zavadskas (2006). Brauers and Zavadskas (2010) developed the MOORA into MULTIMOORA method that is a robust and effective MADM technique. In this paper, we generate a new version of the MULTIMOORA approach for targetbased decision making with interval data to choose appropriate biomaterials. The normalization technique is based on a novel formula of interval distance of interval numbers. Furthermore, preference degree of interval numbers is utilized for calculating extremum and ranking. Thus, we endeavor to decrease degenerating interval numbers by applying all potentials of interval computations.

The remainder of the paper is organized as follows. "Literature review" presents a categorized survey of the related studies. "The crisp target-based MULTIMOORA method" introduces the crisp target-based norm, the subordinate parts of the crisp target-based MULTIMOORA, and the final rankings obtained based on the dominance theory. In "Interval numbers", the principles, arithmetic, and distance formulas of interval numbers besides explanation about interval comparison are provided. In "The proposed interval target-based MULTIMOORA method", we present the interval target-based norm, the subordinate parts of the interval target-based MULTIMOORA, and the final rankings. In "Application of the proposed method in biomaterials selection", we discuss two practical biomaterial selection problems for hip and knee joint prostheses. In "Conclusion", concluding remarks and directions for future research are stated.

The derivation of the proposed method can be summarized in the flowchart shown in Fig. 1. After normalization stage, the algorithm is divided into three branches related to subordinate parts of the interval target-based MULTIMOORA method and finally the final ranking list is calculated by integration of subordinate rankings.

\section{Literature review}

\section{Survey on applications of MADM techniques in material selection}

MADM techniques have been used for materials selection in different applications. Bakhoum and Brown (2013) integrated the analytic hierarchy approach (AHP), TOPSIS, and Shannon entropy methods to choose materials for structural beams. Liu et al. (2013b) employed the ordered weighted averaging (OWA) operator in the VIKOR approach to find an appropriate material for a product subjected to high temperature environment. Anojkumar et al. (2015) utilized the fuzzy analytical hierarchy process (FAHP) with the TOPSIS and VIKOR methods for materials selection in sugar industry. Shanian et al. (2008) utilized a revised Simos' method with the elimination and choice expressing the reality (ELECTRE) technique to make a decision-making model for a materials selection problem relating to a non-heat-treatable cylindrical thermal loaded conductor cover sheet. Karande and Chakraborty (2012) presented a MADM model based on multi-objective optimization on the basis of ratio analysis (MOORA) to choose the best material for four applications, including flywheel, cryogenic storage tank, material operating in high temperature oxygen-rich environment, and sailing boat mast. Liu et al. (2013a) applied interval 2-tuple linguistic VIKOR method combined with subjective and objective significance coefficients to rank candidate materials in two practical problems regarding automotive component and 
Eq. (34)

Construct an interval decision matrix from ratings of candidate alternatives on the attributes

Eq. (35)

(n)

(2q. (35)

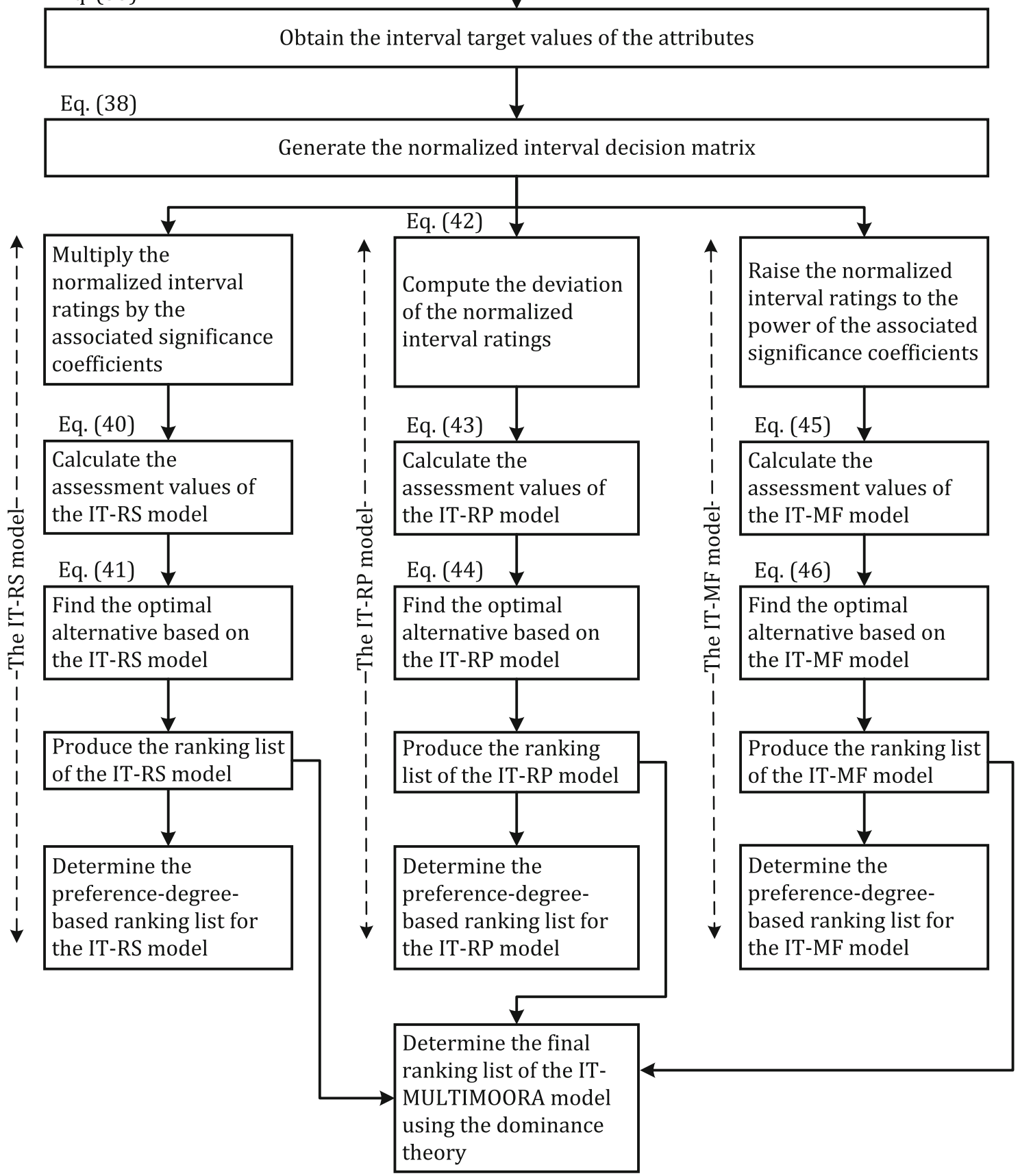

Fig. 1 Flowchart of the interval target-based MULTIMOORA method

flywheel. Peng and Xiao (2013) used a hybrid methodology based on the method of preference ranking organization method for enrichment evaluations (PROMETHEE) and the analytic network process (ANP) for bush materials selection as a part of the design process of a split journal bearing. Hafezalkotob and Hafezalkotob (2016b) extended the MULTIMOORA method with fuzzy numbers and Shannon entropy significance coefficients of attributes to find suitable material for an automobile component. Hafezalkotob and Hafezalkotob (2016c) suggested a riskbased fuzzy axiomatic design model with the integrated Shannon significance coefficients of attributes to select 
industrial gas turbine blade material. Some researchers have focused on the applications of MADM methods in biomaterials selection (Bahraminasab and Jahan 2011; Bahraminasab et al. 2014; Hafezalkotob and Hafezalkotob 2015; Jahan 2012; Jahan and Edwards 2013a, 2013b; Jahan et al. 2011).

\section{Survey on the target-based MADM methods}

Decision-making models with target-based attributes have recently received special attention. Jahan and Edwards (2015) discussed the applications of target-based normalization techniques in MADM methods. Hafezalkotob and Hafezalkotob (2015) tackled two biomaterials selection problems using the target-based MULTIMOORA approach with integrated significance coefficients of attributes. Liu et al. (2014) introduced a hybrid approach by integrating ANP model based on the decision-making trial and evaluation laboratory (DEMATEL) technique and the targetbased VIKOR method to select material for bush of a split journal bearing. Jahan et al. (2012) defined a target-based normalization technique to develop a TOPSIS method for application in electrical insulating materials selection. Jahan et al. (2011) introduced a target-based VIKOR technique for a case study on materials selection related to hip prosthesis. Bahraminasab and Jahan (2011) applied the target-based VIKOR to choose the femoral component of knee prosthesis. Jahan and Edwards (2013b) extended the TOPSIS and VIKOR approaches with target values of attributes and integrated significance coefficients of attributes to find the optimal material for the femoral element of a hip prosthesis. Jahan and Edwards (2013a) developed the target-based VIKOR technique with interval data for a biomaterials selection problem about knee prosthesis. Xue et al. (2016) employed a novel target-based norm in a multi-attributive border approximation area comparison (MABAC) model based on interval-valued intuitionistic fuzzy (IVIF) numbers to select the best material for hip implant.

\section{Survey on the interval MADM methods}

A variety of MADM techniques have been developed based on interval data. Jahanshahloo et al. (2006) introduced an extension of TOPSIS to solve decision-making problems with interval data. Jahanshahloo et al. (2009) created an interval TOPSIS methodology supported on interval efficiency. Yue (2011) extended the TOPSIS approach based on interval data. Sayadi et al. (2009) developed the VIKOR method with interval numbers. Dou et al. (2014) extended the VIKOR and TOPSIS models based on interval numbers and reciprocal judgment matrix. Sayadi and Makui (2012) suggested an interval-based ELECTRE III. Kracka and Zavadskas (2013) formulated an interval MULTIMOORA based on the Moore interval computation. Dymova et al. (2013) presented a direct interval model of TOPSIS based on the distance between midpoints of interval numbers. Stanujkic et al. (2014) extended the ratio system part of the MOORA technique with interval data to select a grinding circuit. Hafezalkotob et al. (2016) presented an extended MULTIMOORA method with interval decision matrix based on interval arithmetic and preference degree of intervals. Fa-Dong et al. (2010) introduced a novel intervalbased MADM approach based on the idea of loss aversion. Pan et al. (2000) used the composite utility variance and linear additive utility function to derive an interval MADM technique.

\section{Survey on developments and applications of the MULTIMOORA method}

The MOORA and MULTIMOORA approaches have been employed in different applications. Datta et al. (2013) extended the MULTIMOORA approach based on intervalvalued gray numbers to produce rankings of industrial robots. Baležentis and Zeng (2013) developed the MULTIMOORA technique with interval-valued fuzzy numbers to select a manager in a personnel selection problem. Liu et al. (2014) assessed the risk of failure modes for the prevention of infant abduction employing the fuzzy MULTIMOORA technique. Stanujkic (2016) developed the ratio system approach of the MOORA method for group decision-making based on interval-valued triangular fuzzy numbers. Mishra et al. (2015) applied the fuzzy MULTIMOORA method to formulate a decision model for supplier/partner selection problem. Deliktas and Ustun (2015) consolidated the fuzzy MULTIMOORA approach and multi-choice conic goal programming for application in student selection problem. Zavadskas et al. (2015) employed the interval-valued intuitionistic fuzzy numbers to extend the MULTIMOORA method for group decision-making. Liu et al. (2015) consolidated the 2-tuple DEMATEL approach and fuzzy MULTIMOORA technique for ranking healthcare waste treatment technologies. Hafezalkotob and Hafezalkotob (2016a) inserted the objective significance coefficients based on Shannon entropy in an extended MULTIMOORA model for materials selection. Baležentis and Baležentis (2014) surveyed the applications and developments of the MULTIMOORA technique.

\section{Research gap}

To the best of the authors' knowledge, no study has developed the MULTIMOORA method with target-based attributes under uncertainty. In this paper, we extend the target-based MULTIMOORA proposed by Hafezalkotob and Hafezalkotob (2015) with interval data to choose 
suitable biomaterials for hip and knee prostheses. The proposed methodology is an inclusive form of the original MULTIMOORA technique and can be used in traditional selection problems in which beneficial and non-beneficial attributes only exist with or without uncertainty of data. The novelties of this study are as follows:

- We use the concept of interval distance to produce novel interval target-based normalization technique. Interval data is considered both for target values of attributes and alternatives ratings on attributes. For this purpose, we introduce a new formula for interval distance.

- We attempt to minimize degeneration of intervals by utilizing the interval computations, including interval arithmetic, interval distances, and the preference degree in the model. A preference matrix is applied based on the concept of the preference degree of interval numbers to generate extremum and ranking of interval numbers.

- For the three parts of the proposed model, we create preference degree-based ranking lists through calculating relative preference degrees for the arranged assessment values.

\section{The crisp target-based MULTIMOORA method}

An MADM problem starts with a decision matrix $\mathbf{X}$. The rating of the decision matrix, i.e., $x_{i j}$, indicates the response (also called performance) of alternative $A_{i}$ to attribute $a_{j}$, in which $i=1,2, \ldots, m$ and $j=1,2, \ldots, n$. Significance coefficient $w_{j}$ is assumed to attach relative importance for each attribute. The significance coefficients of attributes fulfill $\sum_{j=1}^{n} w_{j}=1$. In addition to beneficial and nonbeneficial attributes, target values for some attributes are considered in target-based MADM techniques. A crisp target-based MADM problem, including decision matrix, target values, and significance coefficients of attributes can be denoted as:

$$
\begin{gathered}
\left.\mathbf{T}=\begin{array}{ccccc}
a_{1} & \cdots & a_{j} & \cdots & a_{n} \\
{\left[\bar{t}_{1}\right.} & \cdots & \bar{t}_{j} & \cdots & \bar{t}_{n}
\end{array}\right] \\
\mathbf{X}=\left[\begin{array}{ccccc}
\bar{x}_{11} & \cdots & \bar{x}_{1 j} & \cdots & \bar{x}_{1 n} \\
\vdots & & \vdots & & \vdots \\
\bar{x}_{i 1} & \cdots & \bar{x}_{i j} & \cdots & \bar{x}_{i n} \\
\vdots & & \vdots & & \vdots \\
\bar{x}_{m 1} & \cdots & \bar{x}_{m j} & \cdots & \bar{x}_{m n}
\end{array}\right] A_{1} \\
A_{i} \\
\vdots \\
A_{m}
\end{gathered}
$$

The target (also called the goal or the most favorable) value, i.e., $t_{j}$, for an attribute can be defined as the maximum or minimum of the ratings of alternatives on that attribute or a given quantity considered by decision-makers. The target values of attributes are expressed as follows:

$t_{j}= \begin{cases}\max _{i} x_{i j}, & \text { if } j \in I, \\ \min _{i} x_{i j}, & \text { if } j \in J, \\ g_{j}, & \text { if } j \in K,\end{cases}$

in which $I, J$, and $K$ represent the sets of beneficial, nonbeneficial, and target-based attributes, respectively. $g_{j}$ stands for the goal value of target-based attribute.

\section{The crisp target-based norm}

In traditional MADM methods, norm equation transforms ratings of decision matrix to comparable and dimensionless values called normalized ratings considering beneficial and non-beneficial attributes. However, a new normalization technique is needed to take account of goal values in target-based MADM techniques. Hafezalkotob and Hafezalkotob (2015) introduced a normalization technique for the crisp target-based MULTIMOORA approach:

$f_{i j}=e^{-s_{i j}}$,

in which $s_{i j}$ is:

$$
s_{i j}=\frac{\left|x_{i j}-t_{j}\right|}{\left[\max \left\{\max _{i} x_{i j}, t_{j}\right\}-\min \left\{\min _{i} x_{i j}, t_{j}\right\}\right]} .
$$

Equation (3) actually determines the normalized distance of a rating $x_{i j}$ from the associated target value $t_{j}$. The normalization technique can also be employed in traditional MULTIMOORA approach in which beneficial and non-beneficial attributes only exist.

\section{The crisp target-based ratio system}

The assessment value of the crisp target-based ratio system, i.e., $Y_{i}$, can be formulated as follows (Hafezalkotob and Hafezalkotob 2015):

$Y_{i}=\sum_{j=1}^{n} w_{j} f_{i j}$.

The optimal alternative based on this technique has the maximum assessment value (Hafezalkotob and Hafezalkotob 2015):

$A_{\mathrm{T}-\mathrm{RS}}^{+}=\left\{A_{i} \mid \max _{i} Y_{i}\right\}$,

in which "T-RS" stands for "target-based ratio system". By arranging the assessment values in descending order, the ranking list of the crisp target-based ratio system is obtained. 


\section{The crisp target-based reference point approach}

The deviation of normalized rating $f_{i j}$ from normalized target value, i.e., 1, is calculated as (Hafezalkotob and Hafezalkotob 2015):

$D_{i j}=1-f_{i j}$.

The assessment value of the crisp target-based reference point approach, i.e., $Z_{i}$, is derived as (Hafezalkotob and Hafezalkotob 2015):

$Z_{i}=\max _{j} w_{j} D_{i j}$

The optimal alternative based on this approach has the minimum assessment value (Hafezalkotob and Hafezalkotob 2015):

$A_{\mathrm{T}-\mathrm{RP}}^{+}=\left\{A_{i} \mid \min _{i} Z_{i}\right\}$,

in which "T-RP" denotes "target-based reference point approach". By organizing the assessment values in ascending order, the ranking list of the crisp target-based reference point approach can be computed.

\section{The crisp target-based full multiplicative form}

The significance coefficients have to be considered as exponents in the full multiplicative form (Brauers and Zavadskas 2012). Thus, the assessment value of the crisp target-based full multiplicative form, i.e., $U_{i}$, can be expressed as (Hafezalkotob and Hafezalkotob 2015):

$U_{i}=\prod_{j=1}^{n}\left(f_{i j}\right)^{w_{j}}$.

Similar to the crisp target-based ratio system, the optimal alternative based on this approach is the option with the maximum of associated assessment value:

$A_{\mathrm{T}-\mathrm{MF}}^{+}=\left\{A_{i} \mid \max _{i} U_{i}\right\}$,

in which "T-MF" is an abbreviation for "target-based full multiplicative form". By sorting the assessment values in descending order, the ranking list of the crisp target-based reference point approach can be calculated.

\section{Final ranking list of the crisp target-based MULTIMOORA method}

The ranks of the subordinate parts of the crisp target-based MULTIMOORA method are integrated into the final ranking using the theory of dominance (Hafezalkotob and Hafezalkotob 2015).

\section{Interval numbers}

Vagueness of information can be expressed using uncertain values like interval, gray, fuzzy, stochastic, and linguistic numbers. In real-world decision-making problems, many quantities are presented as a range of data with only lower and upper limits. Such problems can be handled with the aid of interval-based MADM methods. To formulate the interval target-based MULTIMOORA method, some mathematical computations and principles of intervals are necessary that are described in the following sections.

\section{Mathematical principles of intervals}

Some definitions related to interval mathematics have been used in this paper that are as follows (Trindade et al. 2010):

D1 (Interval) Let $y^{L}$ and $y^{U} \in \mathbb{R}$ be such that $y^{L} \leq y^{U}$. The set $\bar{y}=\left\{y \in \mathbb{R} \mid y^{L} \leq y \leq y^{U}\right\}$ is called a real interval and also shown as $\bar{y}=\left[y^{L}, y^{U}\right]$. The set of all real intervals is represented by $\square \mathbb{R}$.

D2 (Inclusion order) Let $\bar{y}$ and $\bar{z} \in \mathbb{R}$. $\bar{y} \subseteq \bar{z}$ if only $y^{L} \geq z^{L}$ and $y^{U} \leq z^{U}$.

D3 (Kulisch-miranker order) Let $\bar{y}$ and $\bar{z} \in \mathbb{R} \cdot \bar{y} \leq \overline{\mathrm{z}}$, if $y^{L} \leq z^{L}$ and $y^{U} \leq z^{U}$. Thus, $\bar{y}=\bar{z}$, if $y^{L}=z^{L}$ and $y^{U}=z^{U}$.

D4 (Positive, negative, and non-negative). An interval, $\bar{y}$, is positive if $y^{L}>0$, negative if $y^{U}<0$, and non-negative if $y^{L} \geq 0$

D5 (midpoint of an interval). Let $\bar{y} \in \mathbb{R}$. The midpoint of $\bar{y}$ is calculated as:

$\operatorname{pm}(\bar{y})=y^{M}=\frac{y^{L}+y^{U}}{2}$.

\section{Interval arithmetic}

If $\bar{y}=\left[y^{L}, y^{U}\right]$ and $\bar{z}=\left[z^{L}, z^{U}\right]$ are two non-negative real interval numbers and $k$ is a non-negative real crisp number, then the algebra is obtained based on Moore interval arithmetic (Moore 1979):

$\bar{y}+\bar{z}=\left[y^{L}+z^{L}, y^{U}+z^{U}\right]$

$\bar{y}-\bar{z}=\left[y^{L}-z^{U}, y^{U}-z^{L}\right]$

$\bar{y} \cdot \bar{z}=\left[y^{L} \cdot z^{L}, y^{U} \cdot z^{U}\right]$,

$\bar{y} / \bar{z}=\left[y^{L} / z^{U}, y^{U} / z^{L}\right]$ with $z^{L}$ and $z^{U} \neq 0$, 
$k \cdot \bar{y}=\left[k \cdot y^{L}, k \cdot y^{U}\right]$.

The exponentiation formula for the base $\bar{y}$, i.e., a nonnegative real interval number, and the exponent $k$, i.e., a non-negative real crisp number, is calculated based on Eq. (15) as follows:

$$
\begin{aligned}
& (\bar{y})^{k}=\left[\left(y^{L}\right)^{k},\left(y^{U}\right)^{k}\right], \\
& (\bar{y})^{-k}=\left[\left(y^{U}\right)^{-k},\left(y^{L}\right)^{-k}\right] .
\end{aligned}
$$

\section{Distance between intervals}

The interval distance between intervals $\bar{y}=$ $\left\{y \in \mathbb{R} \mid y^{L} \leq y \leq y^{U}\right\}$ and $\bar{z}=\left\{z \in \mathbb{R} \mid z^{L} \leq z \leq z^{U}\right\}$ was originally developed by Trindade et al. (2010) as:

$\bar{d}(\bar{y}, \bar{z})=[\inf (|y-z|: y \in \bar{y}$ and $z \in \bar{z}), \sup (|y-z|: y \in \bar{y}$ and $z \in \bar{z})]$

The interval distance, i.e., Equation (20), have three modes (Trindade et al. 2010):

- If $\bar{y} \leq \bar{z}$ and $\bar{y} \cap \bar{z}=\varnothing$, then:

$$
\bar{d}(\bar{y}, \bar{z})=\left[\left(z^{L}-y^{U}\right),\left(z^{U}-y^{L}\right)\right]
$$

- If $\bar{y} \leq \bar{z}$ and $\bar{y} \cap \bar{z} \neq \varnothing$, then:

$$
\bar{d}(\bar{y}, \bar{z})=\left[0,\left(z^{U}-y^{L}\right)\right]
$$

- If $\bar{y} \subseteq \bar{z}$, then:

$$
\bar{d}(\bar{y}, \bar{z})=\left[0, \max \left\{\left(y^{U}-z^{L}\right),\left(z^{U}-y^{L}\right)\right\}\right]
$$

We summarize the modes of the interval distance as follows:
Different metrics for calculation of the distance between real intervals as a crisp value exist in the literature (Dymova et al. 2013; Khezerloo et al. 2011; Moore et al. 2009). However, we define a more robust formula for the crisp distance of two intervals through calculating the midpoint of $\bar{d}^{*}(\bar{y}, \bar{z})$, i.e., Equation (25), as follows:

$$
\begin{aligned}
& d^{*}(\bar{y}, \bar{z})=\operatorname{pm}\left(\bar{d}^{*}(\bar{y}, \bar{z})\right) \\
& = \begin{cases}\frac{\min \left\{\left|\mathrm{y}^{\mathrm{L}}-\mathrm{z}^{\mathrm{U}}\right|,\left|\mathrm{y}^{\mathrm{U}}-\mathrm{z}^{\mathrm{L}}\right|\right\}+\left|\mathrm{y}^{\mathrm{M}}-\mathrm{z}^{\mathrm{M}}\right|}{2}, & \text { if } \bar{y} \cap \bar{z}=\varnothing, \\
\frac{\left|y^{M}-z^{M}\right|}{2}, & \text { if } \bar{y} \cap \bar{z} \neq \varnothing .\end{cases}
\end{aligned}
$$

The reason of robustness of $d^{*}(\bar{y}, \bar{z})$ is due to considering two conditional parts, whereas all the traditional metrics derive the crisp distance of two intervals as a single formula whether the two intervals have or do not have intersection.

\section{Interval comparison, extremum, and ranking}

The preference degree of $\bar{y}=\left[y^{L}, y^{U}\right]$ over $\bar{z}=\left[z^{L}, z^{U}\right]$, represented by $P(\bar{y}>\bar{z}$ ), is obtained as (Wang et al. 2005):

$P(\bar{y}>\bar{z})=\frac{\max \left\{0, \mathrm{y}^{\mathrm{U}}-\mathrm{z}^{\mathrm{L}}\right\}-\max \left\{0, \mathrm{y}^{\mathrm{L}}-\mathrm{z}^{\mathrm{U}}\right\}}{y^{U}-y^{L}+z^{U}-z^{L}}$

The following definitions and properties apply to the preference degree of one interval over the other (Wang et al. 2005):

- $P(\bar{z}>\bar{y})=1-P(\bar{y}>\bar{z})$. If $\bar{y}=\bar{z}$ then $P(\bar{y}>\bar{z})=$ $P(\bar{z}>\bar{y})=0.5$.

- If $P(\bar{y}>\bar{z})>P(\bar{z}>\bar{y})$, then $\bar{y}$ is said to be superior to $\bar{z}$ to the degree of $P(\bar{y}>\bar{z})$, shown by $\bar{y}^{P(\bar{y}>\bar{z})} \bar{z}$; If

$$
\bar{d}(\bar{y}, \bar{z})= \begin{cases}{\left[\min \left\{\left|y^{L}-z^{U}\right|,\left|y^{U}-z^{L}\right|\right\}, \max \left\{\left|y^{L}-z^{U}\right|,\left|y^{U}-z^{L}\right|\right\}\right],} & \text { if } \bar{y} \cap \bar{z}=\varnothing \\ {\left[0, \max \left\{\left|y^{L}-z^{U}\right|,\left|y^{U}-z^{L}\right|\right\}\right],} & \text { if } \bar{y} \cap \bar{z} \neq \varnothing .\end{cases}
$$

However, Eq. (24) is a general formula for interval distance and may contain some defects in practice. For example, the formula does not sensitive to the degree of intersection and also inclusion of two interval numbers. To correct the defects, we improve Eq. (24) as follows:

$$
\begin{aligned}
& \bar{d}^{*}(\bar{y}, \bar{z}) \\
& = \begin{cases}{\left[\min \left\{\left|y^{L}-z^{U}\right|,\left|y^{U}-z^{L}\right|\right\},\left|y^{M}-z^{M}\right|\right],} & \text { if } \bar{y} \cap \bar{z}=\varnothing, \\
{\left[0,\left|y^{M}-z^{M}\right|\right],} & \text { if } \bar{y} \cap \bar{z} \neq \varnothing .\end{cases}
\end{aligned}
$$

$P(\bar{y}>\bar{z})=P(\bar{z}>\bar{y})=0.5$, then $\bar{y}$ is said to be indifferent to $\bar{z}$, denoted by $\bar{y} \sim \bar{z}$; If $P(\bar{z}>\bar{y})>P(\bar{y}>\bar{z})$, then $\bar{y}$ is said to be inferior to $\bar{z}$ to the degree of $P(\bar{z}>\bar{y})$, represented by $\bar{y}^{P(\bar{z}>\bar{y})} \bar{z}$.

- If $\bar{y} \leq \bar{z}$ and $\bar{y} \cap \bar{z}=\varnothing$, then $P(\bar{y} \geq \bar{z})=0$. If $\bar{y} \leq \bar{z}$ and $\bar{y} \cap \bar{z} \neq \varnothing$, then $0 \leq P(\bar{y} \geq \bar{z}) \leq 0.5$.

- If $\bar{y} \geq \overline{\mathrm{z}}$ and $\bar{y} \cap \bar{z}=\varnothing$, then $P(\bar{y} \geq \bar{z})=1$. If $\bar{y} \geq \bar{z}$ and $\bar{y} \cap \bar{z} \neq \varnothing$, then $0.5 \leq P(\bar{y} \geq \bar{z}) \leq 1$. 
Table 1 Relative preference degrees

Relative preference degree

\begin{tabular}{lllllll}
\hline & $\bar{y}_{1}$ & $\bar{y}_{2}$ & $\cdots$ & $\bar{y}_{\beta}$ & $\cdots$ & $\bar{y}_{\delta}$ \\
\hline $\bar{y}_{1}$ & $P\left(\bar{y}_{1}>\bar{y}_{1}\right)$ & $P\left(\bar{y}_{1}>\bar{y}_{2}\right)$ & $\cdots$ & $P\left(\bar{y}_{1}>\bar{y}_{\beta}\right)$ & $\cdots$ & $P\left(\bar{y}_{1}>\bar{y}_{\delta}\right)$ \\
$\bar{y}_{2}$ & $P\left(\bar{y}_{2}>\bar{y}_{1}\right)$ & $P\left(\bar{y}_{2}>\bar{y}_{2}\right)$ & $\cdots$ & $P\left(\bar{y}_{2}>\bar{y}_{\beta}\right)$ & $\cdots$ & $P\left(\bar{y}_{2}>\bar{y}_{\delta}\right)$ \\
$\vdots$ & $\vdots$ & $\vdots$ & & $\vdots$ & & $\vdots$ \\
$\bar{y}_{\alpha}$ & $P\left(\bar{y}_{\alpha}>\bar{y}_{1}\right)$ & $P\left(\bar{y}_{\alpha}>\bar{y}_{2}\right)$ & $\cdots$ & $P\left(\bar{y}_{\alpha}>\bar{y}_{\beta}\right)$ & $\cdots$ & $P\left(\bar{y}_{\alpha}>\bar{y}_{\delta}\right)$ \\
$\vdots$ & $\vdots$ & $\vdots$ & & $\vdots$ & & $\vdots$ \\
$\bar{y}_{\delta}$ & $P\left(\bar{y}_{\delta}>\bar{y}_{1}\right)$ & $P\left(\bar{y}_{\delta}>\bar{y}_{2}\right)$ & $\cdots$ & $P\left(\bar{y}_{\delta}>\bar{y}_{\beta}\right)$ & $\cdots$ & $P\left(\bar{y}_{\delta}>\bar{y}_{\delta}\right)$ \\
\hline
\end{tabular}

To find extremum (i.e., maximization or minimization) and rank a set of intervals $\left\{\bar{y}_{1}, \bar{y}_{2}, \ldots, \bar{y}_{\delta}\right\}(\delta=$ the number of intervals), preference degree matrix and preference matrix are introduced as follows (Rezaei 2016):

In Table $1, P\left(\bar{y}_{\alpha}>\bar{y}_{\beta}\right)$ is the relative preference degree calculated based on Eq. (27):

$P\left(\bar{y}_{\alpha}>\bar{y}_{\beta}\right)=\frac{\max \left\{0, \mathrm{y}_{\alpha}^{\mathrm{U}}-\mathrm{y}_{\beta}^{\mathrm{L}}\right\}-\max \left\{0, \mathrm{y}_{\alpha}^{\mathrm{L}}-\mathrm{y}_{\beta}^{\mathrm{U}}\right\}}{y_{\alpha}^{U}-y_{\alpha}^{L}+y_{\beta}^{U}-y_{\beta}^{L}}$,

in which $\alpha$ and $\beta$ are the indices stand for the column and row of matrix of preference degrees, respectively. If two degenerate interval numbers, i.e., crisp values, exist consecutively in the set of intervals, i.e., $y_{\alpha}^{L}=y_{\alpha}^{U}$ or $y_{\beta}^{L}=y_{\beta}^{U}$, a tiny increment, e.g., $1 \times 10^{-6}$, can be added to the upper limits or subtracted from the lower limits to avoid the zero denominator of Eq. (28).

In Table 2, $P_{\alpha \beta}$ is the relative preference defined as:

$P_{\alpha \beta}= \begin{cases}1, & \text { if } P\left(\bar{y}_{\alpha}>\bar{y}_{\beta}\right)>0.5, \\ 0, & \text { if } P\left(\bar{y}_{\alpha}>\bar{y}_{\beta}\right) \leq 0.5 .\end{cases}$

The relative preferences of each row of the preference matrix are added to generate the aggregate preference as follows:

$A P\left(\bar{y}_{\alpha}\right)=\sum_{\beta=1}^{\delta} P_{\alpha \beta}$,

in which $0 \leq A P\left(\bar{y}_{\alpha}\right) \leq(\delta-1)$.
The maximum and minimum of set of intervals $\left\{\bar{y}_{1}, \bar{y}_{2}, \ldots, \bar{y}_{\alpha}, \ldots, \bar{y}_{\delta}\right\}$ as well as the rank of $\bar{y}_{\delta}$ are computed using Eq. (30), respectively, as:

$$
\begin{aligned}
& \max _{\alpha} \bar{y}_{\alpha}=\max _{\alpha} A P\left(\bar{y}_{\alpha}\right) \\
& \min _{\alpha} \bar{y}_{\alpha}=\min _{\alpha} A P\left(\bar{y}_{\alpha}\right) \\
& \operatorname{rank}\left(\bar{y}_{\alpha}\right)=\operatorname{rank}\left(A P\left(\bar{y}_{\alpha}\right)\right)
\end{aligned}
$$

\section{The proposed interval target-based MULTIMOORA method}

We formulate the proposed methodology using the crisp target-based MULTIMOORA and the intervals computations. An extended MADM problem with interval target values of attributes and interval decision matrix has the following form:

$$
\begin{aligned}
\overline{\mathbf{T}} & \left.=\begin{array}{ccccc}
a_{1} & \cdots & a_{j} & \cdots & a_{n} \\
{\left[\bar{t}_{1}\right.} & \cdots & \bar{t}_{j} & \cdots & \bar{t}_{n}
\end{array}\right] \\
\overline{\mathbf{X}} & =\left[\begin{array}{ccccc}
\bar{x}_{11} & \cdots & \bar{x}_{1 j} & \cdots & \bar{x}_{1 n} \\
\vdots & & \vdots & & \vdots \\
\bar{x}_{i 1} & \cdots & \bar{x}_{i j} & \cdots & \bar{x}_{i n} \\
\vdots & & \vdots & & \vdots \\
A_{1} \\
\vdots \\
A_{i} \\
\vdots \\
\bar{x}_{m 1} & \cdots & \bar{x}_{m j} & \cdots & \bar{x}_{m n}
\end{array}\right] A_{m} \\
\mathbf{W} & =\left[\begin{array}{lllll}
w_{1} & \cdots & w_{j} & \cdots & w_{n}
\end{array}\right]
\end{aligned}
$$

Interval rating $\bar{x}_{i j}=\left[x_{i j}^{L}, x_{i j}^{U}\right]$ shows the uncertain response of alternative $A_{i}$ to attribute $a_{j}$ with interval target value $\bar{t}_{j}$, in which $i=1,2, \ldots, m$ and $j=1,2, \ldots, n$. Decision-makers consider crisp significance coefficient $w_{j}$ for each attribute that satisfies $\sum_{j=1}^{n} w_{j}=1$. The interval target values of attributes are determined as:

$\bar{t}_{j}= \begin{cases}\max _{i} \bar{x}_{i j}, & \text { if } j \in I, \\ \min _{i} \bar{x}_{i j}, & \text { if } j \in J, \\ \bar{g}_{j}, & \text { if } j \in K,\end{cases}$

in which $I, J$, and $K$ are associated with beneficial, non-

\begin{tabular}{|c|c|c|c|c|c|c|c|c|c|}
\hline \multicolumn{7}{|c|}{ Relative preference } & \multirow[t]{2}{*}{ Aggregate preference } & \multirow[t]{2}{*}{ Extremum } & \multirow[t]{2}{*}{ Ranking } \\
\hline & $\bar{y}_{1}$ & $\bar{y}_{2}$ & $\cdots$ & $\bar{y}_{\beta}$ & $\cdots$ & $\bar{y}_{\delta}$ & & & \\
\hline $\bar{y}_{1}$ & $P_{11}$ & $P_{12}$ & $\cdots$ & $P_{1 \beta}$ & $\cdots$ & $P_{1 \delta}$ & $A P\left(\bar{y}_{1}\right)$ & - & $\operatorname{rank}\left(\bar{y}_{1}\right)$ \\
\hline $\bar{y}_{2}$ & $P_{21}$ & $P_{22}$ & $\cdots$ & $P_{2 \beta}$ & $\ldots$ & $P_{2 \delta}$ & $A P\left(\bar{y}_{2}\right)$ & - & $\operatorname{rank}\left(\bar{y}_{2}\right)$ \\
\hline$\vdots$ & $\vdots$ & $\vdots$ & & $\vdots$ & & $\vdots$ & $\vdots$ & & $\vdots$ \\
\hline $\bar{y}_{\alpha}$ & $P_{\alpha 1}$ & $P_{\alpha 2}$ & $\ldots$ & $P_{\alpha \beta}$ & $\ldots$ & $P_{\alpha \delta}$ & $A P\left(\bar{y}_{\alpha}\right)$ & Extremum & $\operatorname{rank}\left(\bar{y}_{\alpha}\right)=1$ \\
\hline$\vdots$ & $\vdots$ & $\vdots$ & & $\vdots$ & & $\vdots$ & $\vdots$ & $\vdots$ & $\vdots$ \\
\hline $\bar{y}_{\delta}$ & $P_{\delta 1}$ & $P_{\delta 2}$ & $\ldots$ & $P_{\delta \beta}$ & $\ldots$ & $P_{\delta \delta}$ & $A P\left(\bar{y}_{\delta}\right)$ & - & $\operatorname{rank}\left(\bar{y}_{\delta}\right)$ \\
\hline
\end{tabular}
beneficial, and target-based attributes, respectively. $\bar{g}_{j}$
Table 2 Relative and aggregate preferences for determining the extremum and ranking list of a set of intervals 
represents the interval goal value of each target-based attribute. The maximum and minimum of ratings on each attribute can be obtained employing Eqs. (31) and (32), respectively.

\section{The interval target-based norm}

The target-based norm, i.e., Equation (3), can be improved as follows:

$f_{i j}^{*}=e^{-s_{i j}^{*}}$

in which $s_{i j}^{*}$ is:

$s_{i j}^{*}=\frac{\left|x_{i j}-t_{j}\right|}{\max _{i}\left|x_{i j}-t_{j}\right|}$.

Equation (36) that is the normalized distance of a rating from the target value can be used as modified norm for target-based MADM problems.

We develop the modified norm, i.e., Eq. (36), for application in interval target-based MULTIMOORA model. The normalized interval ratings are as follows:

$\bar{f}_{i j}^{*}=e^{-\bar{s}_{i j}^{*}}$

in which $\bar{s}_{i j}^{*}$ is obtained using the crisp and interval distances of intervals, i.e., Eqs. (25) and (26) as follows:

$\bar{s}_{i j}^{*}=\frac{\bar{d}^{*}\left(\bar{x}_{i j}, \bar{t}_{j}\right)}{\max _{i} d^{*}\left(\bar{x}_{i j}, \bar{t}_{j}\right)}$

The crisp distance is utilized in the denominator of $\bar{s}_{i j}^{*}$ to avoid zero.

\section{The interval target-based ratio system}

The assessment value of the interval target-based ratio system, i.e., $\bar{Y}_{i}$, is the sum of the products of normalized interval ratings of alternative $A_{i}$ and the associated significance coefficients on all attributes:

$\bar{Y}_{i}=\sum_{j=1}^{n} w_{i} \bar{f}_{i j}^{*}$.

The optimal alternative based on the interval targetbased ratio system has the maximum assessment value and is determined using Eq. (31):

$A_{\mathrm{IT}-\mathrm{RS}}^{+}=\left\{A_{i} \mid \max _{i} \bar{Y}_{i}\right\}$,

in which "IT-RS" stands for "interval target-based ratio system". The assessment values are organized in descending order employing Eq. (33) to generate the ranking list of the interval target-based ratio system. The ranking list can be developed to a preference degree-based ranking list by computing the relative preference degrees for the arranged assessment values utilizing Eq. (27).

\section{The interval target-based reference point approach}

The deviation of the normalized interval rating $\bar{f}_{i j}^{*}$ is calculated using the interval distance formula, i.e., Eq (25):

$\bar{D}_{i j}^{*}=\bar{d}^{*}\left([1,1], \bar{f}_{i j}^{*}\right)$.

The assessment value of the interval target-based reference point approach is calculated employing Eq. (31):

$\bar{Z}_{i}=\max _{j} w_{j} \bar{D}_{i j}^{*}$

The optimal alternative based on the interval targetbased reference point approach has the minimum assessment value and is obtained using Eq. (32):

$A_{\mathrm{IT}-\mathrm{RP}}^{+}=\left\{A_{i} \mid \min _{i} \bar{Z}_{i}\right\}$,

in which "IT-RP" stands for "interval target-based reference point approach". The assessment values are arranged in ascending order employing Eq. (33) to produce the ranking list of the interval target-based reference point approach. The ranking list can be developed to a preference degree-based ranking list by determining the relative preference degrees for the arranged assessment values employing Eq. (27).

\section{The interval target-based full multiplicative form}

The assessment value of the interval target-based full multiplicative form, i.e., $\bar{U}_{i}$, is the product of the normalized interval ratings regarding alternative $A_{i}$ raised to the power of the associated significance coefficients on all attributes:

$\bar{U}_{i}=\prod_{j=1}^{n}\left(\bar{f}_{i j}^{*}\right)^{w_{i}}$.

The optimal alternative for the interval target-based full multiplicative form has the maximum assessment value and is calculated utilizing Eq. (31):

$A_{\mathrm{IT}-\mathrm{MF}}^{+}=\left\{A_{i} \mid \max _{i} \bar{U}_{i}\right\}$,

in which "IT-MF" stands for "interval target-based full multiplicative form". The assessment values are sorted in descending order based on Eq. (33) to find the ranking list of the interval target-based full multiplicative form. The ranking list can be developed to a preference degree-based ranking list by computing the relative preference degrees for the arranged assessment values applying Eq. (27). 


\section{Final ranking list of the interval target-based MULTIMOORA method}

Based on the dominance theory, we integrate the subordinate ranks (i.e., rankings of the IT-RS, IT-RP, and IT-MF techniques) into the IT-MULTIMOORA ranking list. For determining final ranks based on the dominance theory, a circular reasoning may be employed. The dominance theory is evolved based on propositions, including dominance, being dominated, transitivity, and equability (Brauers and Zavadskas 2012).

\section{Application of the proposed method in biomaterials selection}

Recently, the number of materials employed for production of surgical implants has considerably increased. The variety of biomaterials includes metallic, ceramic, polymeric, and composite materials. Different tissues of human body can be replaced by implants. Metallic, ceramic, and composite materials are usually utilized for hard tissues such as bones and joints. Whereas soft tissues like skin and blood vessels can be replaced with polymeric materials. The biocompatibility requirements are important issues in the process of designing implants and the selection of biomaterials (Farag 2013). Biocompatibility generally denotes the ability of a material to perform appropriately without producing an adverse effect. For example, the difference between elastic modulus relating to biomaterial of implant and the surrounding tissue has to be minimized to decrease stress concentration (Jahan 2012). Therefore, the elastic modulus is a target-based attribute in biomaterials selection for surgical implants. Properties of materials often presented as uncertain data in references of materials science and selection. We discuss two case studies about biomaterials selection for femoral components of hip and knee prostheses.

\section{Biomaterials selection for the femoral component of hip joint prosthesis}

We present a practical case concerning the selection of the appropriate biomaterial for the femoral component of a hip prosthesis in this example. Farag (1979) originally discussed this practical case. He derived a target-based LOP model to choose an optimal biomaterial for the application. This biomaterials selection problem has also been discussed in other studies (Hafezalkotob and Hafezalkotob 2015; Jahan 2012; Jahan and Edwards 2013b; Jahan et al. 2011; Xue et al. 2016). Figure 2 illustrates a schematic view of hip joint prosthesis and its elements. A typical hip prosthesis is composed of three essential parts: the acetabular cup,

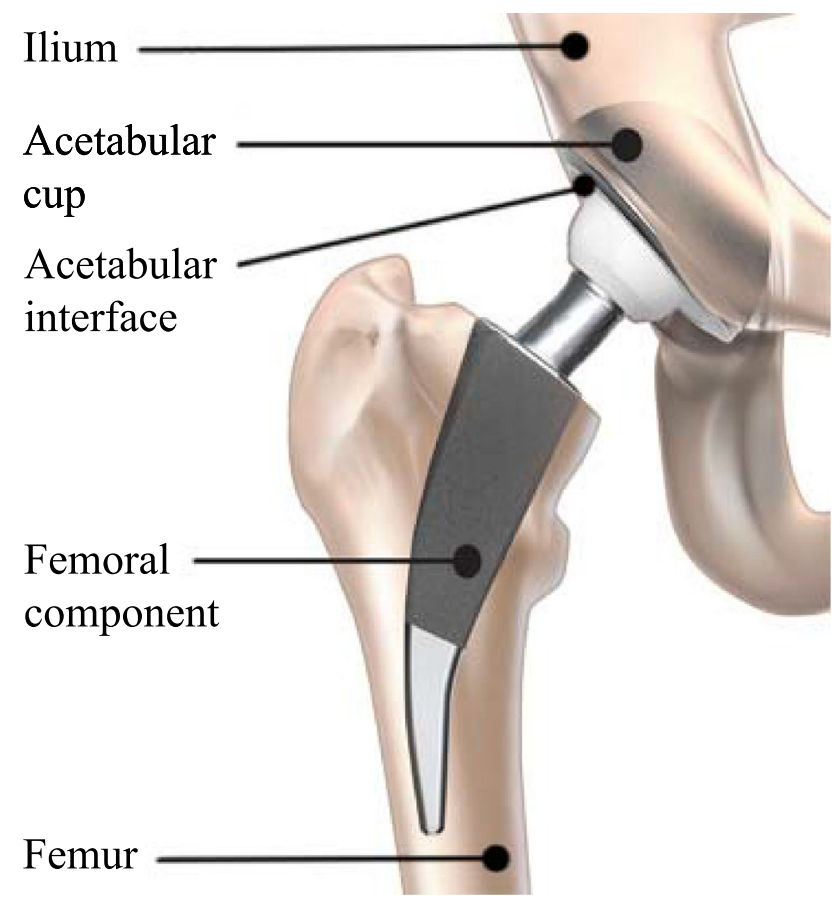

Fig. 2 Components of a typical hip joint prosthesis (Hafezalkotob and Hafezalkotob 2015)

acetabular interface, and femoral component. The femoral component is a metallic or composite rod cemented in femur bone. A ceramic ball head is commonly attached to the end of the component that acts as the femoral head. The femoral component may also be manufactured with a built-in head. The pelvic socket (acetabulum) is substituted with a rigid or soft spherical shell called the acetabular cup (Farag 2013). An abrasive wear resistant substance is placed between the femoral component and the acetabular cup named the acetabular interface (Jahan and Edwards 2013b).

The ordinary materials for the femoral element of a hip prosthesis are cobalt chrome or titanium, and stainless steel. Table 3 shows eleven candidate biomaterials as alternatives $(m=11)$ and their properties as nine attributes $(n=9)$ for the problem. Significance coefficients and target values of the attributes are also indicated in Table 3. The target values are considered near the properties of the femur. Density and elastic modulus are the target-based properties. The only non-beneficial attribute is cost. Other properties are the beneficial attributes.

We present an interval decision matrix, i.e., Table 4, based on the crisp decision matrix for the problem available in the study of Jahan et al. (2011). The ratings on the last five material properties, i.e., tissue tolerance, corrosion resistance, toughness, wear resistance, and cost, are quantified linguistic values between 0 and 10 . The target values for the six beneficial and the single non-beneficial properties are obtained employing Eq. (35). Based on Eq. (38), the material ratings of Table 4 are normalized into 
Table 3 Alternatives and attributes for biomaterials selection of the femoral component of a hip prosthesis (Example 1)

\begin{tabular}{|c|c|c|c|c|c|}
\hline \multicolumn{2}{|c|}{ Candidate materials (alternatives) } & \multicolumn{4}{|c|}{ Properties of candidate materials (attributes) } \\
\hline Material name & Material ID & Property name & Unit & Significance coefficient & Property type \\
\hline Stainless steel 316 & M1 & Elastic modulus & GPa & 0.080 & Target-based $\left(\bar{g}_{1}=[13,15]\right)$ \\
\hline Stainless steel 317 & M2 & Density & $\mathrm{g} / \mathrm{cm}^{3}$ & 0.080 & Target-based $\left(\bar{g}_{2}=[1.8,2.4]\right)$ \\
\hline Stainless steel 321 & M3 & Tensile strength & MPa & 0.080 & Beneficial \\
\hline Stainless steel 347 & M4 & Fatigue strength & $\mathrm{MPa}$ & 0.120 & Beneficial \\
\hline Co-Cr alloy (castable) & M5 & Tissue tolerance & - & 0.200 & Beneficial \\
\hline Co-Cr alloy (wrought) & M6 & Corrosion resistance & - & 0.200 & Beneficial \\
\hline Pure titanium & M7 & Toughness & - & 0.080 & Beneficial \\
\hline Ti-6Al-4 V & M8 & Wear resistance & - & 0.080 & Beneficial \\
\hline Epoxy-70\% glass & M9 & Cost & - & 0.080 & Non-beneficial \\
\hline Epoxy-63\% carbon & M10 & & & & \\
\hline Epoxy-62\% aramid & M11 & & & & \\
\hline
\end{tabular}

Material ID Material identification number

Table 4 Interval decision matrix for Example 1

\begin{tabular}{|c|c|c|c|c|c|c|c|c|c|}
\hline $\begin{array}{l}\text { Material } \\
\text { ID }\end{array}$ & $\begin{array}{l}\text { Elastic } \\
\text { modulus }\end{array}$ & Density & $\begin{array}{l}\text { Tensile } \\
\text { strength }\end{array}$ & $\begin{array}{l}\text { Fatigue } \\
\text { strength }\end{array}$ & $\begin{array}{l}\text { Tissue } \\
\text { tolerance }\end{array}$ & $\begin{array}{l}\text { Corrosion } \\
\text { resistance }\end{array}$ & Toughness & $\begin{array}{l}\text { Wear } \\
\text { resistance }\end{array}$ & Cost \\
\hline M1 & {$[187,213]$} & {$[7.0,9.0]$} & {$[491,543]$} & {$[330,370]$} & {$[9.4,10]$} & {$[6.6,7.0]$} & {$[7.5,8.0]$} & {$[7.5,8.0]$} & {$[1.0,1.1]$} \\
\hline M2 & {$[187,213]$} & {$[7.0,9.0]$} & {$[598,662]$} & {$[391,439]$} & {$[8.5,9.0]$} & {$[6.6,7.0]$} & {$[9.4,10]$} & {$[8.0,8.5]$} & {$[1.1,1.2]$} \\
\hline M3 & {$[187,213]$} & {$[6.9,8.9]$} & {$[579,641]$} & {$[386,434]$} & {$[8.5,9.0]$} & {$[6.6,7.0]$} & {$[9.4,10]$} & {$[7.5,8.0]$} & {$[1.1,1.2]$} \\
\hline M4 & {$[187,213]$} & {$[7.0,9.0]$} & {$[617,683]$} & {$[405,455]$} & {$[8.5,9.0]$} & {$[6.6,7.0]$} & {$[9.4,10]$} & {$[7.9,8.4]$} & {$[1.2,1.3]$} \\
\hline M5 & {$[223,253]$} & {$[7.2,9.4]$} & {$[622,688]$} & {$[400,450]$} & {$[9.4,10]$} & {$[8.5,9.0]$} & {$[2.0,2.1]$} & {$[9.4,10]$} & {$[3.7,3.9]$} \\
\hline M6 & {$[226,258]$} & {$[7.9,10.3]$} & {$[850,942]$} & {$[565,635]$} & {$[9.4,10]$} & {$[8.5,9.0]$} & {$[9.4,10]$} & {$[9.4,10]$} & {$[4.0,4.2]$} \\
\hline M7 & {$[103,117]$} & {$[3.9,5.1]$} & {$[522,578]$} & {$[297,333]$} & {$[7.5,8.0]$} & {$[9.4,10]$} & {$[6.6,7.0]$} & {$[7.5,8.0]$} & {$[1.7,1.8]$} \\
\hline M8 & {$[116,132]$} & {$[3.8,5.0]$} & {$[935,1035]$} & {$[462,518]$} & {$[7.5,8.0]$} & {$[9.4,10]$} & {$[6.6,7.0]$} & {$[7.8,8.3]$} & {$[1.9,2.0]$} \\
\hline M9 & {$[21,23]$} & {$[1.8,2.4]$} & {$[645,715]$} & {$[188,212]$} & {$[6.6,7.0]$} & {$[6.6,7.0]$} & {$[3.0,3.2]$} & {$[6.6,7.0]$} & {$[3.0,3.2]$} \\
\hline M10 & {$[52,60]$} & {$[1.4,1.8]$} & {$[531,589]$} & {$[160,180]$} & {$[6.6,7.0]$} & {$[6.6,7.0]$} & {$[3.0,3.2]$} & {$[7.1,7.5]$} & {$[9.4,10]$} \\
\hline M11 & {$[27,31]$} & {$[1.2,1.6]$} & {$[408,452]$} & {$[122,138]$} & {$[6.6,7.0]$} & {$[6.6,7.0]$} & {$[3.0,3.2]$} & {$[7.1,7.5]$} & {$[5.0,5.0]$} \\
\hline
\end{tabular}

Material ID Material identification number

dimensionless values of Table 5. The deviations of normalized interval material ratings are obtained employing Eq. (42) as shown in Table 6.

Table 7 displays the assessment indices and ranking lists of the proposed decision-making model besides the rankings of the other approaches that have considered this biomedical problem. The assessment values for the subordinate parts (i.e., the IT-RS, the IT-RP, and the IT-MF) are computed using Eqs. (40), (43), and (45), respectively. The optimal biomaterial based on the IT-RS and the IT-MF models obtained using Eqs. (41) and (46) identically is $A_{\mathrm{IT}-\mathrm{RS}}^{+}=A_{\mathrm{IT}-\mathrm{MF}}^{+}=\mathrm{M} 6$, i.e., Co-Cr alloy (wrought). However, the best biomaterial in the IT-RP model obtained using Eqs. (44) is $A_{\mathrm{IT}-\mathrm{RP}}^{+}=\mathrm{M} 8$, i.e., Ti-6Al-4 V. The ranks for the subordinate parts are obtained utilizing Eq. (33). The final ranking list for the problem is obtained based on the theory of dominance. T-MULTIMOORA (Hafezalkotob and Hafezalkotob 2015), T-TOPSIS (Jahan and Edwards 2013b), T-VIKOR (Jahan et al. 2011), and T-IVIF-MABAC (Xue et al. 2016) methods all introduce M6, i.e., Co-Cr alloy (wrought), as the best option similar to the IT-RS and IT-MF techniques. The preference degree-based ranking lists for the candidate materials are calculated using Eq. (27) (for briefness, the preference degree-based ranking list is abbreviated as the PD ranking list).

- PD ranking list based on the IT-RS model: M6 $\stackrel{93.9 \%}{\succ}$

$$
\begin{aligned}
& \text { M8 } \stackrel{93.3 \%}{\succ} \text { M5 } \stackrel{69.0 \%}{\succ} \text { M } 7 \stackrel{87.7 \%}{\succ} \text { M4 } \stackrel{51.1 \%}{\succ} \text { M } 2 \stackrel{50.1 \%}{\succ} \text { M1 }{ }^{58.0 \%} \\
& \text { M3 } \stackrel{100 \%}{\succ} \text { M9 } \stackrel{90.6 \%}{\succ} \text { M1 } 1 \stackrel{62.7 \%}{\succ} \text { M10 }
\end{aligned}
$$

- PD ranking list based on the IT-RP model: M8 $\succ^{100 \%}$

$$
\begin{aligned}
& \text { M6 }{ }^{61.8 \%} \text { M5 } \stackrel{100 \%}{\succ} \text { M7 } \stackrel{100 \%}{\succ}^{\succ} \text { M1 } \sim \text { M2 } \sim \text { M3 } \sim \text { M4 } \\
& \sim \mathrm{M} 9 \sim \mathrm{M} 10 \sim \mathrm{M} 11
\end{aligned}
$$


Table 5 Normalized interval decision matrix for Example 1

\begin{tabular}{llllllllll}
\hline $\begin{array}{l}\text { Material } \\
\text { ID }\end{array}$ & $\begin{array}{l}\text { Elastic } \\
\text { modulus }\end{array}$ & Density & $\begin{array}{l}\text { Tensile } \\
\text { strength }\end{array}$ & $\begin{array}{l}\text { Fatigue } \\
\text { strength }\end{array}$ & $\begin{array}{l}\text { Tissue } \\
\text { tolerance }\end{array}$ & $\begin{array}{l}\text { Corrosion } \\
\text { resistance }\end{array}$ & Toughness & $\begin{array}{l}\text { Wear } \\
\text { resistance }\end{array}$ & $\begin{array}{l}\text { Cost } \\
\text { M1 }\end{array}$ \\
\hline M2 & {$[0.43,0.46]$} & {$[0.39,0.48]$} & {$[0.41,0.47]$} & {$[0.57,0.65]$} & {$[1.00,1.00]$} & {$[0.33,0.40]$} & {$[0.77,0.83]$} & {$[0.48,0.59]$} & {$[1.00,1.00]$} \\
M3 & {$[0.43,0.46]$} & {$[0.39,0.48]$} & {$[0.50,0.59]$} & {$[0.66,0.76]$} & {$[0.69,0.86]$} & {$[0.33,0.40]$} & {$[1.00,1.00]$} & {$[0.58,0.71]$} & {$[0.99,1.00]$} \\
M4 & {$[0.43,0.46]$} & {$[0.39,0.48]$} & {$[0.52,0.62]$} & {$[0.68,0.78]$} & {$[0.69,0.86]$} & {$[0.33,0.40]$} & {$[1.00,1.00]$} & {$[0.56,0.69]$} & {$[0.98,0.98]$} \\
M5 & {$[0.36,0.39]$} & {$[0.37,0.46]$} & {$[0.53,0.62]$} & {$[0.68,0.77]$} & {$[1.00,1.00]$} & {$[0.69,0.86]$} & {$[0.36,0.38]$} & {$[1.00,1.00]$} & {$[0.72,0.73]$} \\
M6 & {$[0.35,0.38]$} & {$[0.33,0.41]$} & {$[0.84,1.00]$} & {$[1.00,1.00]$} & {$[1.00,1.00]$} & {$[0.69,0.86]$} & {$[1.00,1.00]$} & {$[1.00,1.00]$} & {$[0.70,0.71]$} \\
M7 & {$[0.65,0.67]$} & {$[0.68,0.78]$} & {$[0.43,0.50]$} & {$[0.53,0.60]$} & {$[0.48,0.59]$} & {$[1.00,1.00]$} & {$[0.68,0.72]$} & {$[0.48,0.59]$} & {$[0.92,0.93]$} \\
M8 & {$[0.61,0.63]$} & {$[0.69,0.79]$} & {$[1.00,1.00]$} & {$[0.78,0.90]$} & {$[0.48,0.59]$} & {$[1.00,1.00]$} & {$[0.68,0.72]$} & {$[0.54,0.66]$} & {$[0.90,0.91]$} \\
M9 & {$[0.96,0.97]$} & {$[1.00,1.00]$} & {$[0.56,0.65]$} & {$[0.41,0.45]$} & {$[0.33,0.40]$} & {$[0.33,0.40]$} & {$[0.41,0.43]$} & {$[0.33,0.40]$} & {$[0.78,0.80]$} \\
M10 & {$[0.83,0.84]$} & {$[0.92,1.00]$} & {$[0.44,0.51]$} & {$[0.38,0.42]$} & {$[0.33,0.40]$} & {$[0.33,0.40]$} & {$[0.41,0.43]$} & {$[0.40,0.49]$} & {$[0.36,0.38]$} \\
M11 & {$[0.93,0.95]$} & {$[0.89,0.96]$} & {$[0.34,0.39]$} & {$[0.35,0.39]$} & {$[0.33,0.40]$} & {$[0.33,0.40]$} & {$[0.41,0.43]$} & {$[0.40,0.49]$} & {$[0.63,0.63]$} \\
\hline
\end{tabular}

Material ID Material identification number

Table 6 Deviations of the normalized interval ratings for Example 1

\begin{tabular}{llllllllll}
\hline $\begin{array}{l}\text { Material } \\
\text { ID }\end{array}$ & $\begin{array}{l}\text { Elastic } \\
\text { modulus }\end{array}$ & Density & $\begin{array}{l}\text { Tensile } \\
\text { strength }\end{array}$ & $\begin{array}{l}\text { Fatigue } \\
\text { strength }\end{array}$ & $\begin{array}{l}\text { Tissue } \\
\text { tolerance }\end{array}$ & $\begin{array}{l}\text { Corrosion } \\
\text { resistance }\end{array}$ & Toughness & $\begin{array}{l}\text { Wear } \\
\text { resistance }\end{array}$ & $\begin{array}{l}\text { Cost } \\
\text { M1 }\end{array}$ \\
\hline M2 & {$[0.54,0.56]$} & {$[0.52,0.56]$} & {$[0.53,0.56]$} & {$[0.35,0.39]$} & {$[0.00,0.00]$} & {$[0.60,0.63]$} & {$[0.17,0.20]$} & {$[0.41,0.46]$} & {$[0.00,0.00]$} \\
M3 & {$[0.54,0.56]$} & {$[0.51,0.56]$} & {$[0.43,0.47]$} & {$[0.25,0.30]$} & {$[0.14,0.22]$} & {$[0.60,0.63]$} & {$[0.00,0.00]$} & {$[0.41,0.46]$} & {$[0.00,0.01]$} \\
M4 & {$[0.54,0.56]$} & {$[0.52,0.56]$} & {$[0.38,0.43]$} & {$[0.22,0.27]$} & {$[0.14,0.22]$} & {$[0.60,0.63]$} & {$[0.00,0.00]$} & {$[0.31,0.38]$} & {$[0.02,0.02]$} \\
M5 & {$[0.61,0.63]$} & {$[0.54,0.58]$} & {$[0.38,0.42]$} & {$[0.23,0.27]$} & {$[0.00,0.00]$} & {$[0.14,0.22]$} & {$[0.62,0.63]$} & {$[0.00,0.00]$} & {$[0.27,0.27]$} \\
M6 & {$[0.62,0.63]$} & {$[0.59,0.63]$} & {$[0.00,0.08]$} & {$[0.00,0.00]$} & {$[0.00,0.00]$} & {$[0.14,0.22]$} & {$[0.00,0.00]$} & {$[0.00,0.00]$} & {$[0.29,0.30]$} \\
M7 & {$[0.33,0.34]$} & {$[0.22,0.27]$} & {$[0.50,0.53]$} & {$[0.40,0.44]$} & {$[0.41,0.46]$} & {$[0.00,0.00]$} & {$[0.28,0.30]$} & {$[0.41,0.46]$} & {$[0.07,0.08]$} \\
M8 & {$[0.37,0.38]$} & {$[0.21,0.26]$} & {$[0.00,0.00]$} & {$[0.10,0.16]$} & {$[0.41,0.46]$} & {$[0.00,0.00]$} & {$[0.28,0.30]$} & {$[0.34,0.40]$} & {$[0.09,0.10]$} \\
M9 & {$[0.03,0.03]$} & {$[0.00,0.00]$} & {$[0.35,0.40]$} & {$[0.55,0.57]$} & {$[0.60,0.63]$} & {$[0.60,0.63]$} & {$[0.57,0.58]$} & {$[0.60,0.63]$} & {$[0.20,0.21]$} \\
M10 & {$[0.16,0.17]$} & {$[0.00,0.04]$} & {$[0.49,0.52]$} & {$[0.58,0.60]$} & {$[0.60,0.63]$} & {$[0.60,0.63]$} & {$[0.57,0.58]$} & {$[0.51,0.55]$} & {$[0.62,0.63]$} \\
M11 & {$[0.05,0.06]$} & {$[0.04,0.07]$} & {$[0.61,0.63]$} & {$[0.61,0.63]$} & {$[0.60,0.63]$} & {$[0.60,0.63]$} & {$[0.57,0.58]$} & {$[0.51,0.55]$} & {$[0.37,0.37]$} \\
\hline
\end{tabular}

Material ID Material identification number

- PD ranking list based on the IT-MF model: M6 ${ }^{72.8 \%} \mathrm{M} 8 \stackrel{100 \%}{\succ} \mathrm{M} 5{ }^{55.0 \%} \mathrm{M} 7 \stackrel{92.1 \%}{\succ} \mathrm{M} 4 \stackrel{51.1 \%}{\succ} \mathrm{M} 2 \stackrel{56.8 \%}{\succ}$
$\mathrm{M} 1 \stackrel{50.3 \%}{\succ} \mathrm{M} 3 \stackrel{100 \%}{\succ} \mathrm{M} 9 \stackrel{78.3 \%}{\succ} \mathrm{M} 11 \stackrel{56.9 \%}{\succ} \mathrm{M} 10$

We use Spearman rank correlation coefficient to indicate correspondence between the final ranking list of the proposed method and the outcomes of other techniques shown in Table 7. The Spearman coefficient is a real number between -1 and 1 . The value 1 represents exact connection of the compared rankings, whereas the value -1 denotes entire opposition. Figure 3 illustrates correlation between the outcome of the paper and those of the other approaches for the problem through calculating the Spearman coefficients. T-TOPSIS (Jahan and Edwards 2013b) with Spearman coefficient 0.97 shows the maximum connection with our method. T-IVIF-ELECTRE (Xue et al. 2016) has the lowest value of Spearman coefficient, i.e., 0.70.

\section{Biomaterials selection for the femoral component of a knee joint prosthesis}

As the second example, a biomaterials selection problem about the femoral component of knee prosthesis is solved using the proposed methodology. This practical case has been previously tackled utilizing other target-based MADM techniques (Bahraminasab and Jahan 2011; Hafezalkotob and Hafezalkotob 2015; Jahan and Edwards 2013a). Knee replacement is a set of biomaterials that substitute for the weight-bearing elements of a knee joint to alleviate disability and pain. Standard knee prosthesis comprises three important features, i.e., the tibial tray, tibial insert, and femoral component. Figure 4 displays an illustration of the parts of knee prosthesis.

The femoral component is a round-ended implant forming the natural shape of the distal femur. The common 


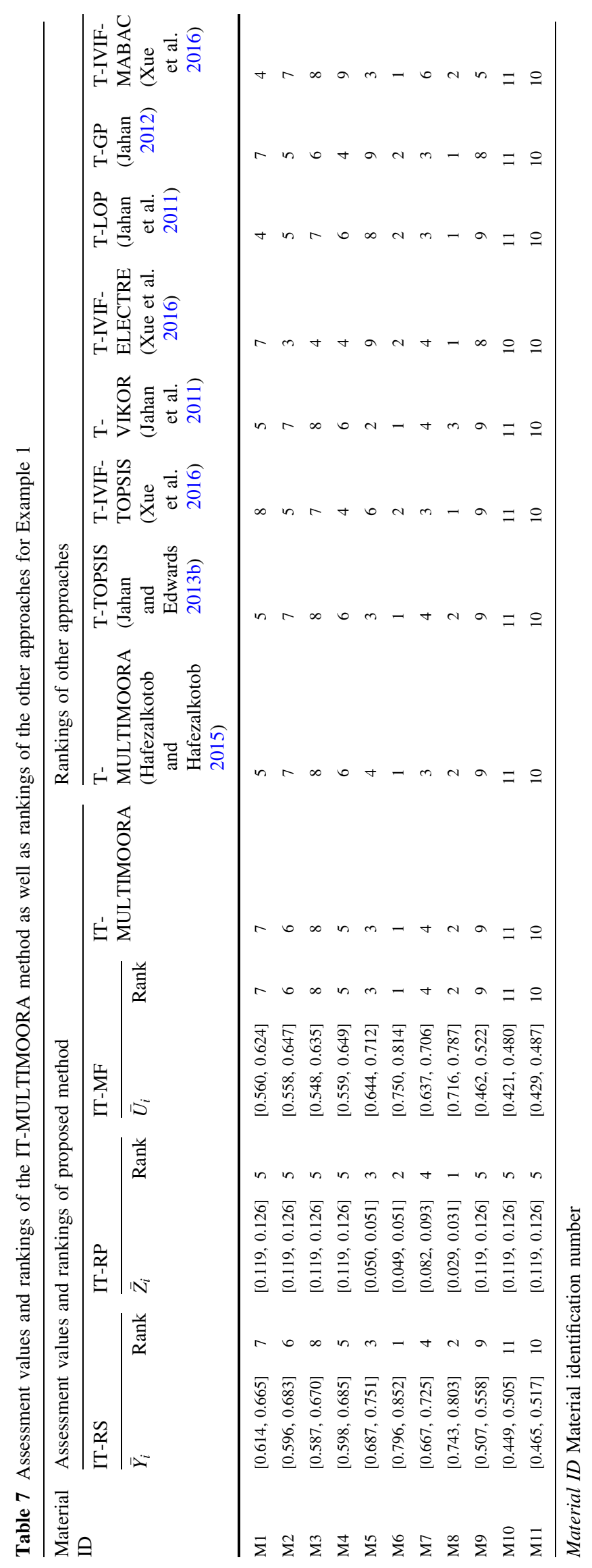


Fig. 3 Spearman rank correlation between the rankings of the IT-

MULTIMOORA method and the other approaches for Example 1

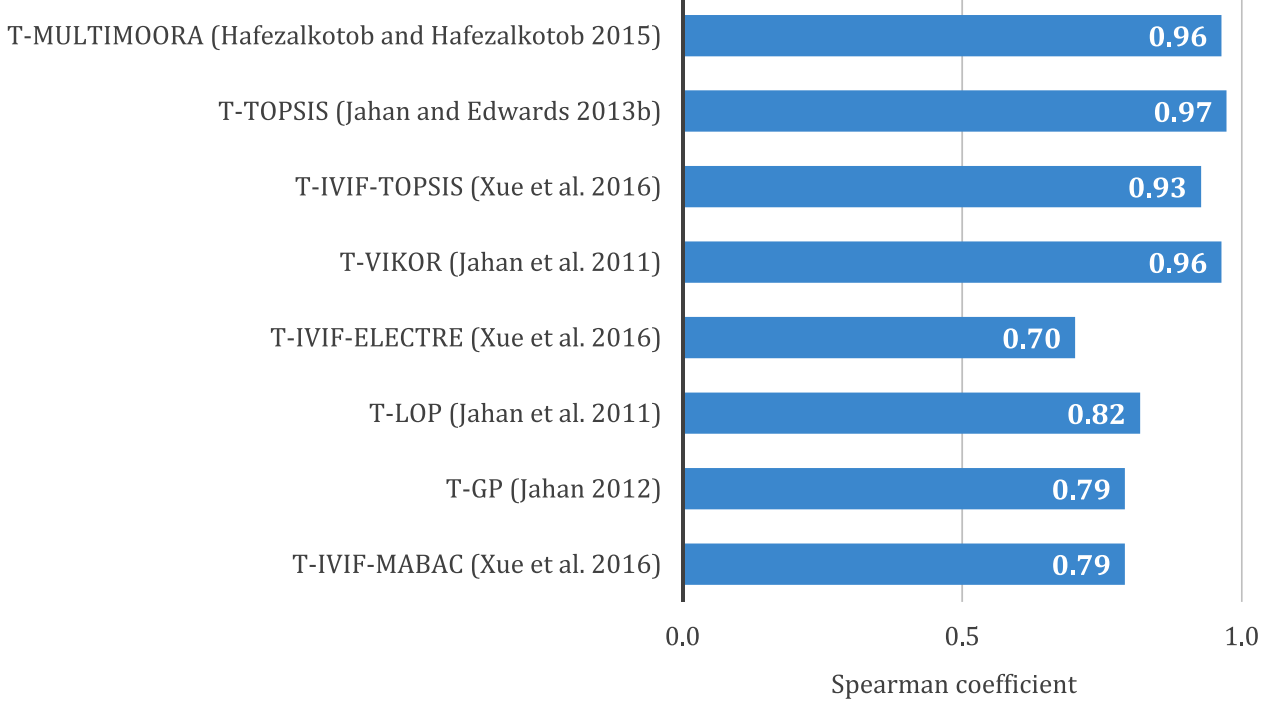

materials employed in production of the femoral component of knee prosthesis are stainless steel, $\mathrm{Co}-\mathrm{Cr}$ alloys, pure titanium, titanium alloys, and NiTi shape-memory alloys (SMAs). In this biomaterials selection problem, ten candidate materials as alternatives $(m=10)$ and seven material properties as attributes $(n=7)$ are considered as listed in Table 8. Similar to Example 1, the target-based properties are density and elastic modulus. Moreover, five beneficial material properties exist in the problem. Table 8 also presents significance coefficients and target values of the material properties.

Table 9 shows the interval decision matrix for Example 2 that is based on the crisp decision matrix presented in the study of Bahraminasab and Jahan (2011). The ratings on the last three material properties, i.e., corrosion resistance, wear resistance, and osseointegration are quantified linguistic values between 0 and 1 . Table 10 lists the normalized material ratings for this biomaterials selection

Fig. 4 Components of a typical knee joint prosthesis (Hafezalkotob and Hafezalkotob 2015)

Table 8 Alternatives and attributes for biomaterials selection of the femoral component of a knee prosthesis (Example 2)

\begin{tabular}{|c|c|c|c|c|c|}
\hline \multicolumn{2}{|l|}{ Candidate materials (alternatives) } & \multicolumn{4}{|c|}{ Properties of candidate materials (attributes) } \\
\hline Material name & Material ID & Property name & Unit & Significance coefficient & Property type \\
\hline Stainless steel 316L (annealed) & M1 & Elastic modulus & GPa & 0.061 & Target-based $\left(\bar{g}_{1}=[15,17]\right)$ \\
\hline Stainless steel 316L (cold-worked) & M2 & Density & $\mathrm{g} / \mathrm{cm}^{3}$ & 0.105 & Target-based $\left(\bar{g}_{2}=[1.1,1.5]\right)$ \\
\hline Co-Cr alloy (wrought) & M3 & Tensile strength & MPa & 0.136 & Beneficial \\
\hline Co-Cr alloy (castable) & M4 & Elongation & $\%$ & 0.105 & Beneficial \\
\hline Pure titanium & M5 & Corrosion resistance & - & 0.179 & Beneficial \\
\hline Ti-6Al-4 V & M6 & Wear resistance & - & 0.229 & Beneficial \\
\hline Ti-6Al-7Nb (wrought) & M7 & Osseointegration & - & 0.185 & Beneficial \\
\hline Ti-6Al-7Nb (hot-forged) & M8 & & & & \\
\hline NiTi (SMA) & M9 & & & & \\
\hline Porous NiTi (SMA) & M10 & & & & \\
\hline
\end{tabular}

Material ID Material identification number 
Table 9 Interval decision matrix for Example 2

\begin{tabular}{lcrrrrrr}
\hline Material ID & Elastic modulus & \multicolumn{1}{c}{ Density } & Tensile strength & Elongation & Corrosion resistance & Wear resistance & Osseointegration \\
\hline M1 & {$[187,213]$} & {$[7.0,9.0]$} & {$[491,543]$} & {$[32,48]$} & {$[0.64,0.70]$} & {$[0.57,0.61]$} & {$[0.57,0.61]$} \\
M2 & {$[187,213]$} & {$[7.0,9.0]$} & {$[818,906]$} & {$[10,14]$} & {$[0.64,0.70]$} & {$[0.72,0.78]$} & {$[0.57,0.61]$} \\
M3 & {$[224,256]$} & {$[7.9,10.3]$} & {$[850,942]$} & {$[10,30]$} & {$[0.72,0.78]$} & {$[0.84,0.90]$} & {$[0.64,0.70]$} \\
M4 & {$[224,256]$} & {$[7.2,9.4]$} & {$[622,688]$} & {$[10,30]$} & {$[0.72,0.78]$} & {$[0.84,0.90]$} & {$[0.64,0.70]$} \\
M5 & {$[94,107]$} & {$[3.9,5.1]$} & {$[522,578]$} & {$[43,65]$} & {$[0.92,1]$} & {$[0.57,0.61]$} & {$[0.72,0.78]$} \\
M6 & {$[105,119]$} & {$[3.9,5.0]$} & {$[935,1035]$} & {$[10,14]$} & {$[0.92,1]$} & {$[0.64,0.70]$} & {$[0.72,0.78]$} \\
M7 & {$[105,120]$} & {$[3.9,5.1]$} & {$[900,946]$} & {$[10,12]$} & {$[0.92,1]$} & {$[0.64,0.70]$} & {$[0.72,0.78]$} \\
M8 & {$[103,117]$} & {$[3.9,5.1]$} & {$[1000,1100]$} & {$[10,15]$} & {$[0.92,1]$} & {$[0.64,0.70]$} & {$[0.72,0.78]$} \\
M9 & {$[48,51]$} & {$[5.7,7.3]$} & {$[1240,1303]$} & {$[10,14]$} & {$[0.92,1]$} & {$[0.92,1]$} & {$[0.48,0.52]$} \\
M10 & {$[14,16]$} & {$[3.7,4.2]$} & {$[949,1051]$} & {$[10,14]$} & {$[0.72,0.78]$} & {$[0.92,1]$} & {$[0.92,1]$} \\
\hline
\end{tabular}

Material ID Material identification number

Table 10 Normalized interval decision matrix for Example 2

\begin{tabular}{|c|c|c|c|c|c|c|c|}
\hline Material ID & Elastic modulus & Density & Tensile strength & Elongation & Corrosion resistance & Wear resistance & Osseointegration \\
\hline M1 & {$[0.43,0.45]$} & {$[0.39,0.46]$} & {$[0.35,0.38]$} & {$[0.69,1.00]$} & {$[0.32,0.42]$} & {$[0.34,0.40]$} & {$[0.42,0.49]$} \\
\hline M2 & {$[0.43,0.45]$} & {$[0.39,0.46]$} & {$[0.57,0.63]$} & {$[0.32,0.46]$} & {$[0.32,0.42]$} & {$[0.54,0.66]$} & {$[0.42,0.49]$} \\
\hline M3 & {$[0.35,0.38]$} & {$[0.33,0.40]$} & {$[0.60,0.66]$} & {$[0.40,0.70]$} & {$[0.44,0.58]$} & {$[0.77,0.95]$} & {$[0.51,0.59]$} \\
\hline M4 & {$[0.35,0.38]$} & {$[0.38,0.45]$} & {$[0.43,0.47]$} & {$[0.40,0.70]$} & {$[0.44,0.58]$} & {$[0.77,0.95]$} & {$[0.51,0.59]$} \\
\hline M5 & {$[0.68,0.70]$} & {$[0.64,0.71]$} & {$[0.37,0.40]$} & {$[1.00,1.00]$} & {$[1.00,1.00]$} & {$[0.34,0.40]$} & {$[0.61,0.72]$} \\
\hline M6 & {$[0.64,0.67]$} & {$[0.65,0.72]$} & {$[0.67,0.75]$} & {$[0.32,0.46]$} & {$[1.00,1.00]$} & {$[0.43,0.52]$} & {$[0.61,0.72]$} \\
\hline M7 & {$[0.64,0.67]$} & {$[0.64,0.71]$} & {$[0.62,0.67]$} & {$[0.31,0.43]$} & {$[1.00,1.00]$} & {$[0.43,0.52]$} & {$[0.61,0.72]$} \\
\hline M8 & {$[0.65,0.67]$} & {$[0.64,0.71]$} & {$[0.74,0.82]$} & {$[0.33,0.47]$} & {$[1.00,1.00]$} & {$[0.43,0.52]$} & {$[0.61,0.72]$} \\
\hline M9 & {$[0.86,0.87]$} & {$[0.48,0.56]$} & {$[1.00,1.00]$} & {$[0.32,0.46]$} & {$[1.00,1.00]$} & {$[1.00,1.00]$} & {$[0.34,0.39]$} \\
\hline M10 & {$[1.00,1.00]$} & {$[0.69,0.73]$} & {$[0.69,0.77]$} & {$[0.32,0.46]$} & {$[0.44,0.58]$} & {$[1.00,1.00]$} & {$[1.00,1.00]$} \\
\hline
\end{tabular}

Material ID Material identification number

Table 11 Deviations of the normalized interval ratings for Example 2

\begin{tabular}{llllllll}
\hline Material ID & Elastic modulus & Density & Tensile strength & Elongation & Corrosion resistance & Wear resistance & Osseointegration \\
\hline M1 & {$[0.55,0.56]$} & {$[0.54,0.57]$} & {$[0.62,0.63]$} & {$[0.00,0.16]$} & {$[0.58,0.63]$} & {$[0.60,0.63]$} & {$[0.51,0.54]$} \\
M2 & {$[0.55,0.56]$} & {$[0.54,0.57]$} & {$[0.37,0.40]$} & {$[0.54,0.61]$} & {$[0.58,0.63]$} & {$[0.34,0.40]$} & {$[0.51,0.54]$} \\
M3 & {$[0.62,0.63]$} & {$[0.60,0.63]$} & {$[0.34,0.37]$} & {$[0.30,0.45]$} & {$[0.42,0.49]$} & {$[0.05,0.14]$} & {$[0.41,0.45]$} \\
M4 & {$[0.62,0.63]$} & {$[0.55,0.59]$} & {$[0.53,0.55]$} & {$[0.30,0.45]$} & {$[0.42,0.49]$} & {$[0.05,0.14]$} & {$[0.41,0.45]$} \\
M5 & {$[0.30,0.31]$} & {$[0.29,0.33]$} & {$[0.60,0.61]$} & {$[0.00,0.00]$} & {$[0.00,0.00]$} & {$[0.60,0.63]$} & {$[0.28,0.33]$} \\
M6 & {$[0.33,0.35]$} & {$[0.28,0.32]$} & {$[0.25,0.29]$} & {$[0.54,0.61]$} & {$[0.00,0.00]$} & {$[0.48,0.53]$} & {$[0.28,0.33]$} \\
M7 & {$[0.33,0.35]$} & {$[0.29,0.33]$} & {$[0.33,0.36]$} & {$[0.57,0.63]$} & {$[0.00,0.00]$} & {$[0.48,0.53]$} & {$[0.28,0.33]$} \\
M8 & {$[0.33,0.34]$} & {$[0.29,0.33]$} & {$[0.18,0.22]$} & {$[0.53,0.60]$} & {$[0.00,0.00]$} & {$[0.48,0.53]$} & {$[0.28,0.33]$} \\
M9 & {$[0.13,0.14]$} & {$[0.44,0.48]$} & {$[0.00,0.00]$} & {$[0.54,0.61]$} & {$[0.00,0.00]$} & {$[0.00,0.00]$} & {$[0.61,0.63]$} \\
M10 & {$[0.00,0.00]$} & {$[0.27,0.29]$} & {$[0.23,0.27]$} & {$[0.54,0.61]$} & {$[0.42,0.49]$} & {$[0.00,0.00]$} & {$[0.00,0.00]$} \\
\hline
\end{tabular}

Material ID Material identification number

problem. The deviations of normalized interval material ratings are collected in Table 11.

The assessment indices and ranking lists of the ITMULTIMOORA model as well as the rankings of the other methods for the practical case are demonstrated in Table 12 .
The optimal biomaterial based on the IT-MULTIMOORA model and its subordinates as well as T-MULTIMOORA (Hafezalkotob and Hafezalkotob 2015) similarly is M9, i.e., NiTi (SMA). However, T-MULTIMOORA (Hafezalkotob and Hafezalkotob 2015) also introduces M10, i.e., Porous 


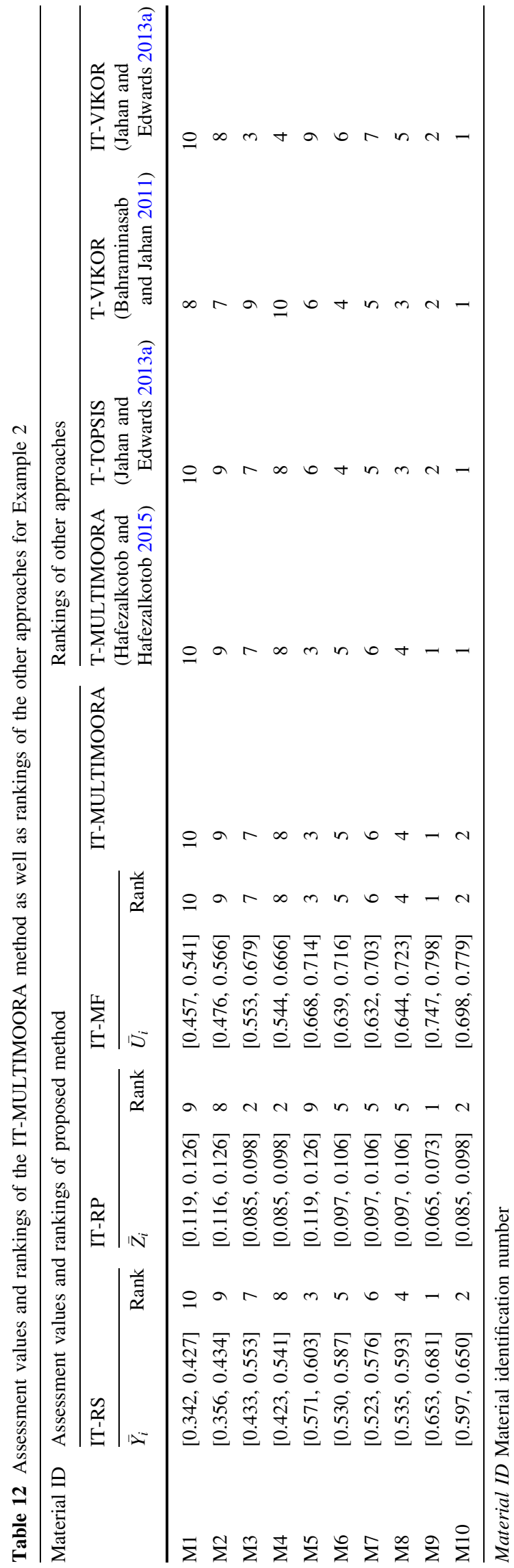

NiTi (SMA), besides M9 as the best options. The preference degree-based ranking lists of IT-RS, IT-RP, and IT-MF models for Example 2 are obtained as follows:

- PD ranking list based on the IT-RS model: M9 $\stackrel{100 \%}{\succ}$

$$
\begin{aligned}
& \text { M10 } \stackrel{92.5 \%}{\succ} \text { M } 5 \stackrel{75.7 \%}{\succ}^{758} 8 \stackrel{55.1 \%}{\succ} \mathrm{M} 6 \stackrel{57}{\succ}^{57.9 \%} \mathrm{M} 7 \stackrel{82.7 \%}{\succ} \mathrm{M} 3 \stackrel{54.7 \%}{\succ} \\
& \mathrm{M} 4 \stackrel{94.7 \%}{\succ} \mathrm{M} 2 \stackrel{56.2 \%}{\succ} \mathrm{M} 1
\end{aligned}
$$

- PD ranking list based on the IT-RP model: M9 $\stackrel{100 \%}{\succ}$

$$
\begin{aligned}
& \mathrm{M} 3 \sim \mathrm{M} 4 \sim \mathrm{M} 10 \stackrel{95.0 \%}{\succ} \mathrm{M} 6 \sim \mathrm{M} 7 \sim \mathrm{M} 8 \stackrel{100 \%}{\succ} \mathrm{M} 2 \stackrel{59.9 \%}{\succ} \\
& \mathrm{M} 1 \sim \mathrm{M} 5
\end{aligned}
$$

- PD ranking list based on the IT-MF model:

$$
\begin{aligned}
& \text { - M9 }{ }^{75.4 \%} \mathrm{M} 10{ }^{87.5 \%} \mathrm{M} 5{ }^{56.0 \%} \mathrm{M} 8 \stackrel{53.8 \%}{\succ} \mathrm{M} 6{ }^{56.8 \%} \mathrm{M} 7 \stackrel{75.8 \%}{\succ}
\end{aligned}
$$

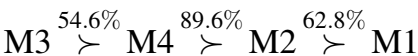

Figure 5 exhibits the connection between the final ranking list of this study and the rankings of the other target-based MADM methods shown in Table 11 for the biomaterials selection problem regarding knee prosthesis. Having an identical ranking list, T-MULTIMOORA (Hafezalkotob and Hafezalkotob 2015) has the maximum correlation with the proposed methodology. IT-VIKOR (Jahan and Edwards 2013a) with Spearman coefficient 0.55 shows the least connection with the proposed IT-MULTIMOORA method.

\section{Conclusion}

Target-based MADM models can aid decision-makers to find the appropriate alternative in practical cases like materials selection problems in which target values of attributes are significant. In many real-world decisionmaking problems, ratings of alternatives on attributes often have some extents of uncertainty. Therefore, structured algorithms are necessary to concurrently consider targetbased attributes and interval numbers in decision-making process. In this paper, we developed an extension of the MULTIMOORA method using interval target values of attributes and interval decision matrix. We suggested a novel equation for interval distance of interval numbers which can be utilized to form normalization technique for interval target-based decision making problems. The utilized interval distance is an improved equation comparing the interval distance formula available in the literature. A preference matrix was generated to find extremum and ranking of intervals. We examined two biomaterials selection problem relating to orthopedic prostheses. A preference degree-based ranking list was generated by calculating the relative preference degrees for the arranged candidate biomaterials in each subordinate part of the proposed methodology. The final ranking lists of the model 
Fig. 5 Spearman rank correlation between the rankings of the ITMULTIMOORA method and the other approaches for Example 2

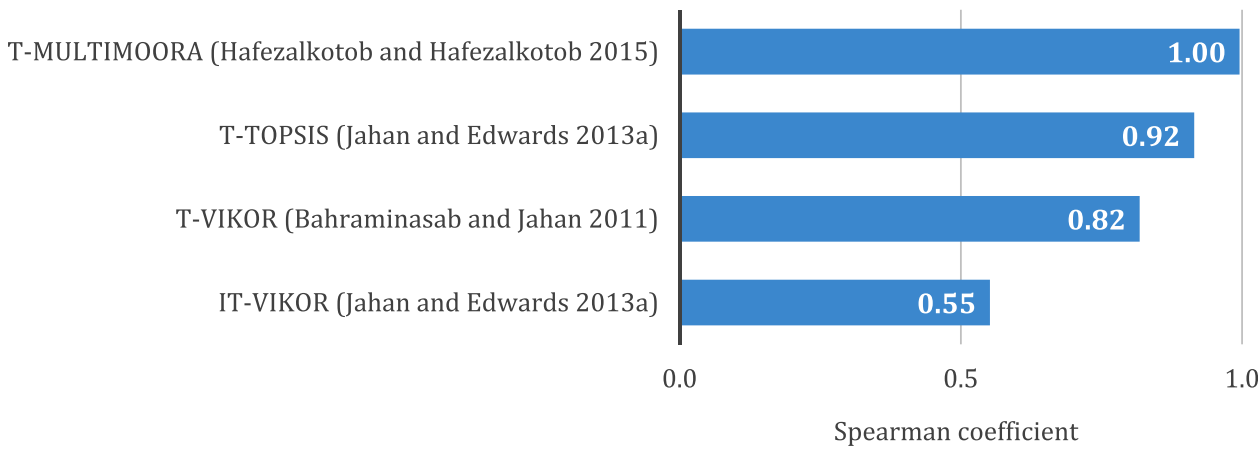

for the problems were compared with the results of other decision-making models.

All previous interval-based MADM models have degenerated intervals from low to high extents. However, we tried to reduce degeneration of interval numbers using different tools of the interval computations. Only in one application that is the denominator of ratios, we inevitably degenerated intervals. That is, we utilized the crisp distance instead of the interval distance for the denominator of ratios.

The ratings of alternatives on their attributes and the target values of the attributes were considered as interval numbers in this study. However, other forms of uncertain data can be considered in prospective extensions of targetbased MULTIMOORA method. For example, the proposed approach can be extended based on the principles of fuzzy computations. In this regard, preference degree of fuzzy numbers and the concept of fuzzy distance can be employed. Derivation of extensions of the proposed method using rough or linguistic data is also appealing. In the practical examples, subjective significance coefficients of the attributes were only considered. However, various forms of objective and integrated significance coefficients may be applied in the uncertain target-based decisionmaking models. Because of the nature of the biomaterial selection problems examined in this paper, only two targetbased attributes exist in each case. However, the number of target-based attributes in other material selection problems may be more. Therefore, such problems highlight the importance of the derived algorithm. In other practical applications like machine selection or waste management, some target-based attributes exist. Thus, the proposed method can help in ranking the candidate alternatives of such problems.

Open Access This article is distributed under the terms of the Creative Commons Attribution 4.0 International License (http://crea tivecommons.org/licenses/by/4.0/), which permits unrestricted use, distribution, and reproduction in any medium, provided you give appropriate credit to the original author(s) and the source, provide a link to the Creative Commons license, and indicate if changes were made.

\section{References}

Aghajani Mir M et al (2016) Application of TOPSIS and VIKOR improved versions in a multi criteria decision analysis to develop an optimized municipal solid waste management model. J Environ Manage 166:109-115

Anojkumar L, Ilangkumaran M, Vignesh M (2015) A decision making methodology for material selection in sugar industry using hybrid MCDM techniques. Int J Mater Product Technol $51: 102-126$

Bahraminasab M, Jahan A (2011) Material selection for femoral component of total knee replacement using comprehensive VIKOR. Mater Des 32:4471-4477

Bahraminasab M, Sahari B, Edwards K, Farahmand F, Jahan A, Hong TS, Arumugam M (2014) On the influence of shape and material used for the femoral component pegs in knee prostheses for reducing the problem of aseptic loosening. Mater Des 55:416-428

Bakhoum ES, Brown DC (2013) A hybrid approach using AHPTOPSIS-entropy methods for sustainable ranking of structural materials. Int J Sustainable Eng 6:212-224

Baležentis T, Baležentis A (2014) A survey on development and applications of the multi-criteria Decision making method MULTIMOORA. J Multicrit Decision Anal 21:209-222

Baležentis T, Zeng S (2013) Group multi-criteria decision making based upon interval-valued fuzzy numbers: an extension of the MULTIMOORA method. Expert Syst Appl 40:543-550

Brauers WKM, Zavadskas EK (2006) The MOORA method and its application to privatization in a transition economy. Control Cybern 35:445-469

Brauers WKM, Zavadskas EK (2010) Project management by MULTIMOORA as an instrument for transition economies. Technol Econ Dev Eco 16:5-24

Brauers WKM, Zavadskas EK (2012) Robustness of MULTIMOORA: a method for multi-objective optimization. Informatica $23: 1-25$

Cavallini C, Giorgetti A, Citti P, Nicolaie F (2013) Integral aided method for material selection based on quality function deployment and comprehensive VIKOR algorithm. Mater Des 47:27-34

Datta S, Sahu N, Mahapatra S (2013) Robot selection based on greyMULTIMOORA approach. Grey Syst Theory Appl 3:201-232

Deliktas D, Ustun O (2015) Student selection and assignment methodology based on fuzzy MULTIMOORA and multichoice goal programming. Internat Trans Oper Res. doi:10.1111/itor. 12185

Dou Y, Zhang P, Jiang J, Yang K, Chen Y (2014) MCDM based on reciprocal judgment matrix: A comparative study of E-VIKOR and E-TOPSIS algorithmic methods with interval numbers. Appl Math Inf Sci 8:1401-1411

Dymova L, Sevastjanov P, Tikhonenko A (2013) A direct interval extension of TOPSIS method. Expert Syst Appl 40:4841-4847 
Fa-Dong C, Xiao Z, Feng K, Zhi-ping F, Xi C (2010) A method for interval multiple attribute decision making with loss aversion. In: Proceedings of the 2010 International Conference of Information Science and Management Engineering (ISME-2010), Shaanxi, China, 2010. IEEE, pp 453-456

Farag MM (1979) Materials and process selection in engineering. Elsevier Science \& Technology, UK

Farag MM (2013) Materials and process selection for engineering design, 3rd edn. CRC, Boca Raton

Hafezalkotob A, Hafezalkotob A (2015) Comprehensive MULTIMOORA method with target-based attributes and integrated significant coefficients for materials selection in biomedical applications. Mater Des 87:949-959

Hafezalkotob A, Hafezalkotob A (2016a) Extended MULTIMOORA method based on Shannon entropy weight for materials selection. J Ind Eng Int 12:1-13

Hafezalkotob A, Hafezalkotob A (2016b) Fuzzy entropy-weighted MULTIMOORA method for materials selection. J Intell Fuzzy Syst 31:1211-1226

Hafezalkotob A, Hafezalkotob A (2016c) Risk-based material selection process supported on information theory: a case study on industrial gas turbine. Appl Soft Comput. doi:10.1016/j.asoc. 2016.09.018

Hafezalkotob A, Hafezalkotob A, Sayadi MK (2016) Extension of MULTIMOORA method with interval numbers: an application in materials selection. Appl Math Model 40:1372-1386

Jahan A (2012) Material selection in biomedical applications: Comparing the comprehensive VIKOR and goal programming models. Int J Mater Struct Integr 6:230-240

Jahan A, Edwards KL (2013a) VIKOR method for material selection problems with interval numbers and target-based criteria. Mater Des 47:759-765

Jahan A, Edwards KL (2013b) Weighting of dependent and targetbased criteria for optimal decision-making in materials selection process: biomedical applications. Mater Des 49:1000-1008

Jahan A, Edwards KL (2015) A state-of-the-art survey on the influence of normalization techniques in ranking: improving the materials selection process in engineering design. Mater Des 65:335-342

Jahan A, Mustapha F, Ismail MY, Sapuan S, Bahraminasab M (2011) A comprehensive VIKOR method for material selection. Mater Des 32:1215-1221

Jahan A, Bahraminasab M, Edwards K (2012) A target-based normalization technique for materials selection. Mater Des 35:647-654

Jahanshahloo GR, Lotfi FH, Izadikhah M (2006) An algorithmic method to extend TOPSIS for decision-making problems with interval data. Appl Math Comput 175:1375-1384

Jahanshahloo GR, Lotfi FH, Davoodi A (2009) Extension of TOPSIS for decision-making problems with interval data: interval efficiency. Math Comput Model 49:1137-1142

Karande P, Chakraborty S (2012) Application of multi-objective optimization on the basis of ratio analysis (MOORA) method for materials selection. Mater Des 37:317-324

Khezerloo S, Allahviranloo T, Khezerloo M (2011) Ranking of fuzzy numbers based on alpha-distance. In: Proceedings of the 7th conference of the European Society for Fuzzy Logic and Technology (EUSFLAT-2011), Aix-les-Bains, France, 2011. Atlantis Press, pp 770-777

Kracka M, Zavadskas EK (2013) Panel building refurbishment elements effective selection by applying multiple-criteria methods. Int J Strateg Prop Manag 17:210-219

Liu H-C, Liu L, Wu J (2013a) Material selection using an interval 2-tuple linguistic VIKOR method considering subjective and objective weights. Mater Des 52:158-167
Liu H-C, Mao L-X, Zhang Z-Y, Li P (2013b) Induced aggregation operators in the VIKOR method and its application in material selection. Appl Math Model 37:6325-6338

Liu H-C, You J-X, Zhen L, Fan X-J (2014) A novel hybrid multiple criteria decision making model for material selection with targetbased criteria. Mater Des 60:380-390

Liu H-C, You J-X, Lu C, Chen Y-Z (2015) Evaluating health-care waste treatment technologies using a hybrid multi-criteria decision making model. Renew Sustain Energy Rev 41:932-942

Mishra S, Sahu AK, Datta S, Mahapatra SS (2015) Application of fuzzy integrated MULTIMOORA method towards supplier/partner selection in agile supply chain. Int J Oper Res 22:466-514

Moore RE (1979) Methods and applications of interval analysis. Society for industrial and applied mathematics, Philadelphia

Moore RE, Kearfott RB, Cloud MJ (2009) Introduction to interval analysis. Society for industrial and applied mathematics, Philadelphia

Murray GT (ed) (1997) Handbook of materials selection for engineering applications. Marcel Dekker Inc, New York

Pan J, Teklu Y, Rahman S, de Castro A (2000) An interval-based MADM approach to the identification of candidate alternatives in strategic resource planning. IEEE Trans Power Syst 15:1441-1446

Peng A-H, Xiao X-M (2013) Material selection using PROMETHEE combined with analytic network process under hybrid environment. Mater Des 47:643-652

Rezaei J (2016) Best-worst multi-criteria decision-making method: Some properties and a linear model. Omega 64:126-130

Sayadi MK, Makui A (2012) A new view to uncertainty in Electre III method by introducing interval numbers. Decis Sci Lett 1:33-38

Sayadi MK, Heydari M, Shahanaghi K (2009) Extension of VIKOR method for decision making problem with interval numbers. Appl Math Model 33:2257-2262

Shanian A, Milani AS, Carson C, Abeyaratne RC (2008) A new application of ELECTRE III and revised Simos' procedure for group material selection under weighting uncertainty. Knowl Based Syst 21:709-720

Stanujkic D (2016) An extension of the ratio system approach of MOORA method for group decision-making based on intervalvalued triangular fuzzy numbers. Technol Econ Dev Eco 22:122-141

Stanujkic D, Magdalinovic N, Milanovic D, Magdalinovic S, Popovic G (2014) An efficient and simple multiple criteria model for a grinding circuit selection based on moora method. Informatica 25:73-93

Trindade RMP, Bedregal BRC, Doria Neto AD, Acioly BM (2010) An interval metric. In: Lazinica A (ed) New advanced technologies. InTech, Rijeka, Croatia, pp 323-340

Wang Y-M, Yang J-B, Xu D-L (2005) A preference aggregation method through the estimation of utility intervals. Comput Oper Res 32:2027-2049

Xue Y-X, You J-X, Lai X-D, Liu H-C (2016) An interval-valued intuitionistic fuzzy MABAC approach for material selection with incomplete weight information. Appl Soft Comput 38:703-713

Yue Z (2011) An extended TOPSIS for determining weights of decision makers with interval numbers. Knowl Based Syst 24:146-153

Zavadskas EK, Antucheviciene J, Razavi Hajiagha SH, Hashemi SS (2015) The interval-valued intuitionistic fuzzy MULTIMOORA method for group decision making in engineering. Math Probl Eng 2015:13, Art ID 560690

Zeng Q-L, Li D-D, Yang Y-B (2013) VIKOR method with enhanced accuracy for multiple criteria decision making in healthcare management. J Med Syst 37:1-9 